OPEN ACCESS

Edited by:

James W. Grau,

Texas A\&M University, United States

Reviewed by:

Peter C. Rowe,

Johns Hopkins University,

United States

James N. Baraniuk,

Georgetown University Medical

Center, United States

*Correspondence:

Gerard Pereira

gpereira@corteneinc.com

Received: 21 April 2021

Accepted: 15 July 2021

Published: 01 September 2021

Citation:

Pereira G, Gillies H, Chanda S, Corbett M, Vernon SD, Milani T and

Bateman L (2021) Acute

Corticotropin-Releasing Factor

Receptor Type 2 Agonism Results in Sustained Symptom Improvement in Myalgic Encephalomyelitis/Chronic

Fatigue Syndrome.

Front. Syst. Neurosci. 15:698240.

doi: 10.3389/fnsys.2021.698240

\section{Acute Corticotropin-Releasing Factor Receptor Type 2 Agonism Results in Sustained Symptom Improvement in Myalgic Encephalomyelitis/Chronic Fatigue Syndrome}

\author{
Gerard Pereira ${ }^{1 *}$, Hunter Gillies ${ }^{1}$, Sanjay Chanda ${ }^{1}$, Michael Corbett ${ }^{1}$, \\ Suzanne D. Vernon ${ }^{2}$, Tina Milani ${ }^{2}$ and Lucinda Bateman ${ }^{2}$ \\ ${ }^{1}$ Cortene Inc., Burlingame, CA, United States, ${ }^{2}$ Bateman Horne Center, Salt Lake City, UT, United States
}

Background: Myalgic encephalomyelitis/chronic fatigue syndrome (ME/CFS) is a complex multi-symptom disease with widespread evidence of disrupted systems. The authors hypothesize that it is caused by the upregulation of the corticotropin-releasing factor receptor type 2 (CRFR2) in the raphé nuclei and limbic system, which impairs the ability to maintain homeostasis. The authors propose utilizing agonist-mediated receptor endocytosis to downregulate CRFR2.

Materials and Methods: This open-label trial tested the safety, tolerability and efficacy of an acute dose of CT38s (a short-lived, CRFR2-selective agonist, with no known off-target activity) in $14 \mathrm{ME} / \mathrm{CFS}$ patients. CT38s was subcutaneously-infused at one of four dose-levels (i.e., infusion rates of $0.01,0.03,0.06$, and $0.20 \mu \mathrm{g} / \mathrm{kg} / \mathrm{h}$ ), for a maximum of $10.5 \mathrm{~h}$. Effect was measured as the pre-/post-treatment change in the mean 28-day total daily symptom score (TDSS), which aggregated 13 individual patient-reported symptoms.

Results: ME/CFS patients were significantly more sensitive to the transient hemodynamic effects of CRFR2 stimulation than healthy subjects in a prior trial, supporting the hypothesized CRFR2 upregulation. Adverse events were generally mild, resolved without intervention, and difficult to distinguish from ME/CFS symptoms, supporting a CRFR2 role in the disease. The acute dose of CT38s was associated with an improvement in mean TDSS that was sustained (over at least 28 days posttreatment) and correlated with both total exposure and pre-treatment symptom severity. At an infusion rate of $0.03 \mu \mathrm{g} / \mathrm{kg} / \mathrm{h}$, mean TDSS improved by $-7.5 \pm 1.9$ (or $-25.7 \%$, $p=0.009$ ), with all monitored symptoms improving.

Conclusion: The trial supports the hypothesis that CRFR2 is upregulated in ME/CFS, and that acute CRFR2 agonism may be a viable treatment approach warranting further study.

Clinical Trial Registration: ClinicalTrials.gov, identifier NCT03613129.

Keywords: myalgic encephalomyelitis chronic fatigue syndrome, ME/CFS, agonist-mediated receptor endocytosis, corticotropin-releasing factor receptor 2, CRF2, serotonin, homeostasis 


\section{INTRODUCTION}

\section{Myalgic Encephalomyelitis/Chronic Fatigue Syndrome}

Myalgic encephalomyelitis/chronic fatigue syndrome (ME/CFS) is a debilitating disease affecting $\sim 20$ million worldwide. It can be triggered by infection, traumatic life events, chemicals, toxins, immunizations, anesthetics, physical trauma, among others (Chu et al., 2019). Its major symptoms include profound fatigue (described as "concrete limbs," "crushing gravity," "not tired"), musculoskeletal pain, cognitive impairment ("brain fog"), orthostatic intolerance (OI), flu-like symptoms and un-refreshing sleep (Chu et al., 2018, 2019). These are exacerbated by any kind of stimulation, including physical, cognitive, emotional (Chu et al., 2018) and even postural change (van Campen et al., 2021), referred to as post-exertional malaise (PEM). ME/CFS patients often have other disorders, including dysautonomia (Naschitz et al., 2004; Newton et al., 2007), insulin resistance (Maloney et al., 2010; Armstrong et al., 2015), immune dysfunction (Straus et al., 1988; Borish et al., 1998; Nicolson et al., 2002; Chia and Chia, 2007; Morris et al., 2014), hypothyroidism (Ruiz-Núñez et al., 2018) and gynecological issues (Boneva et al., 2015). $\mathrm{ME} / \mathrm{CFS}$ is diagnosed by exclusion, treated symptomatically and results in a quality of life lower than in most chronic diseases (Hvidberg et al., 2015). Research has identified abnormalities in neurotransmitters, hormones, autoantibodies, immune cells, cytokines, metabolites, energy substrates, oxidative byproducts, mitochondria, ion channels, gut bacteria, genetics, epigenetics, and brain anatomy, but to date, no single cause explains this dysfunction (Komaroff, 2019).

\section{Etiological Hypothesis}

The authors hypothesize that these abnormalities could all originate from a single pathway, involving the corticotropinreleasing factor (CRF, also known as corticotropin-releasing hormone or $\mathrm{CRH}$ ) system and its regulation of serotonin (5HT) in the limbic system, which controls the response to homeostatic threat (Dedic et al., 2018; Deussing and Chen, 2018; Godoy et al., 2018), usually termed "stress," but avoided here to preclude narrow connotations. This hypothesis synthesizes numerous independent in vivo studies to propose the mechanisms of homeostasis. It rests on three constructs (Figure 1).

First, under homeostatic threat, the CRF system controls the release of $5 H T$ from the dorsal raphé. Within the dorsal raphé (largest of the raphé nuclei and a major source of brain 5HT),

\footnotetext{
Abbreviations: $5 \mathrm{HT}$, serotonin; $5 \mathrm{HT}_{1 \mathrm{~A}}, 5 \mathrm{HT}$ receptor type $1 \mathrm{~A}$; $\mathrm{ADL}$, activities of daily living; AE, adverse event; AUC, area under the plasma concentrationtime curve; BNST, bed nucleus of the stria terminalis; Cmax, maximum plasma concentration; CPET, cardio-pulmonary exercise test; CRF, corticotropin-releasing factor; CRFR1/2, CRF receptor type 1/2; dBP, diastolic blood pressure; FDA, United States Food and Drug Administration; GABA, gamma-aminobutyric acid; $\mathrm{HR}$, heart rate; MAP, mean arterial pressure; MCS, SF-36 mental component score; ME/CFS, myalgic encephalomyelitis/chronic fatigue syndrome; OI, orthostatic intolerance; PCS, SF-36 physical component score; PEM, post-exertional malaise; PI, principal investigator; PK, pharmacokinetic; $\mathrm{SAE}$, serious AE; sBP, systolic blood pressure; SF-36, 36-Item Short Form Survey Instrument; SSRI, selective serotonin reuptake inhibitor; TDSS, total daily symptom score; TEAE, treatmentemergent AE; UCN1/2/3, urocortin 1/2/3.
}

CRF receptor type 1 (CRFR1) is present in the membranes of gamma-aminobutyric acid (GABA) neurons, while CRFR2 is present in the cytoplasm of 5HT neurons-this configuration being associated with a basal level of 5HT output (Waselus et al., 2005; Kirby et al., 2008; Lukkes et al., 2008). Minor homeostatic threat, releasing low levels of CRF in the dorsal raphé, activates CRFR1 to release GABA, which tonically inhibits 5HT downstream (Waselus et al., 2005; Kirby et al., 2008; Lukkes et al., 2008). Major (or prolonged/repeated) threat, releasing high levels of CRF, causes the CRF receptors to redistribute, with CRFR1 internalizing (in GABA neurons), and CRFR2 migrating to the membranes of 5HT neurons (Waselus et al., 2009), where activation releases 5HT downstream (Waselus et al., 2005; Kirby et al., 2008; Lukkes et al., 2008). Thus, the CRF system controls the threat-specific release of 5HT from the dorsal raphé (and possibly other raphé nuclei).

Second, homeostatic threat induces threat- and neuronallyspecific adaptations of CRFR1 and CRFR2 to control limbic 5HT and homeostasis. The limbic system receives threat-related inputs from the sensory (Chanes and Barrett, 2016), autonomic (Berthoud and Neuhuber, 2000), endocrine (Dedic et al., 2018; Deussing and Chen, 2018), metabolic (Tups et al., 2017; Pozo and Claret, 2018) and immune (Silverman et al., 2005; SotoTinoco et al., 2016; Dantzer, 2018; Kipnis, 2018) systems. The authors propose that these inputs engage the CRF system (Dedic et al., 2018; Deussing and Chen, 2018), inducing adaptations in CRFR1/CRFR2 similar to those in the dorsal raphé and observed in vivo, e.g., in the hippocampus (Sananbenesi et al., 2003) or amygdala (Qi et al., 2014), which then modulate 5HT (Hensler, 2006; Charnay and Léger, 2010) and other neuromodulators (Avery and Krichmar, 2017). That is, an initial CRFR1/CRFR2 configuration associated with a basal 5HT output (Waselus et al., 2005; Kirby et al., 2008; Lukkes et al., 2008), similar to a homeostatic set point, adapts by upregulating either CRFR1 or CRFR2 (concomitant with downregulating CRFR1), respectively, decreasing or increasing 5HT to control downstream function. This enables a coordinated threat response of 5HT-related functions, including emotion, motivation, nociception, memory consolidation, regulating extrapyramidal and ventricular systems (Berger et al., 2009; Waselus et al., 2011), motor control (Perrier et al., 2013; Perrier and Cotel, 2015), proprioception (Delhaye et al., 2018), sensory sensitivity (Heath et al., 2006; Petzold et al., 2009; Hurley and Hall, 2011; Obara et al., 2014; Chang et al., 2016; Shimegi et al., 2016), respiration (Hilaire et al., 2010), thermoregulation (Lin et al., 1998; Boulant, 2000), and downstream autonomic, endocrine (Dedic et al., 2018; Deussing and Chen, 2018; Godoy et al., 2018), metabolic (Donovan and Tecott, 2013; Roh et al., 2016; Tups et al., 2017; Pozo and Claret, 2018; Flak et al., 2020; Alonge et al., 2021), and immune (Quintanar and Guzmán-Soto, 2013; Sundman and Olofsson, 2014; Soto-Tinoco et al., 2016; Dantzer, 2018) actions. Importantly, CRFR1/CRFR2 adaptations are both threat- and neuronally-specific. For instance, a high temperature must elevate 5HT in the neurons of the preoptic area of the anterior hypothalamus to provoke cooling (Lin et al., 1998; Boulant, 2000), but without modulating other 5HT neurons, e.g., vision/hearing-related. In contrast, the selective serotonin 


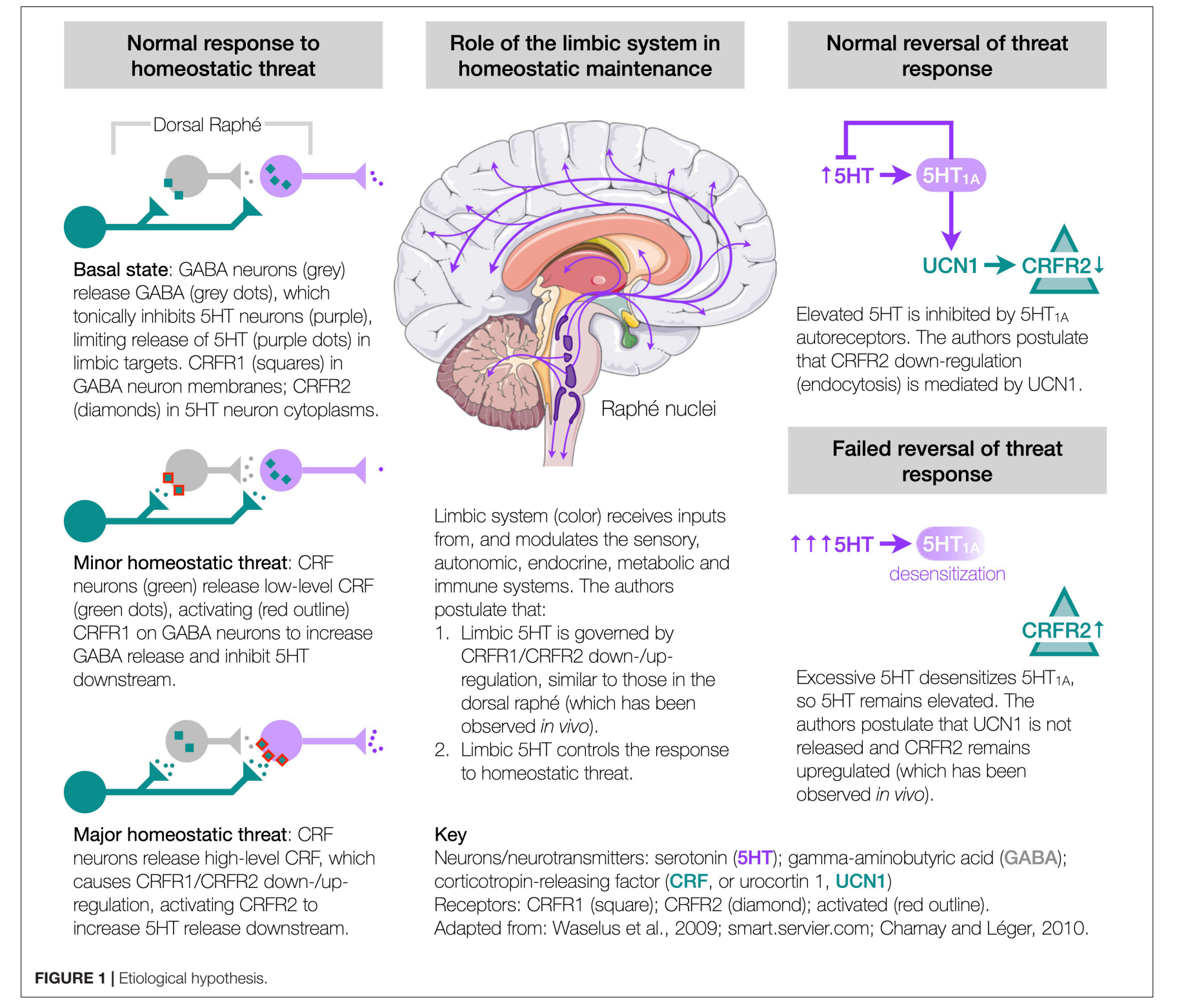

reuptake inhibitors (SSRIs) indiscriminately modulate $5 \mathrm{HT}$, so can cause fever, chills, blurry vision, tinnitus, etc. (Ferguson, 2001). Thus, threat- and neuronally-specific CRFR1/CRFR2 adaptions control limbic 5HT and downstream function.

Third, CRFR2 (and CRFR1) are susceptible to maladaptation. Following threat resolution, basal configurations are restored, with $5 \mathrm{HT}_{1 A}$ autoreceptors inhibiting further $5 \mathrm{HT}$ release (Neufeld-Cohen et al., 2012), and CRFR2 downregulating via endocytosis (Markovic et al., 2008, 2011; Hauger et al., 2013), likely mediated by urocortin 1 (UCN1) (Dos Santos et al., 2015) competitively displacing CRF-respective CRFR2 binding affinities are 0.4 and $44.5 \mathrm{nmol}$ (Deussing and Chen, 2018). However, excessive $5 \mathrm{HT}$ can desensitize the $5 \mathrm{HT}_{1 A}$ autoreceptors leaving 5HT elevated (Rozeske et al., 2011), which the authors propose disrupts the restorative process and fails to downregulate CRFR2 at threat cessation, observed in vivo as increases in
CRFR2 expression (Lukkes et al., 2009), or increased membranebound CRFR2 in the dorsal raphé (Waselus et al., 2009; Wood et al., 2013), hippocampus (Sananbenesi et al., 2003), amygdala (coincident with decreased CRFR1 expression) (Qi et al., 2014), and bed nucleus of the stria terminalis (BNST) (Lebow et al., 2012), yet absent in the BNST under different provocation (Elharrar et al., 2013), so supporting the threat-specificity of CRFR1/CRFR2 adaptation. Such CRFR2 upregulations can accumulate and bias the system toward elevated 5HT release (Lukkes et al., 2009; Wood et al., 2013). ME/CFS develops more in conditions of adversity (Heim et al., 2006; Nater et al., 2011), and patients show evidence of overactive limbic circuits (Nakatomi et al., 2014), elevated brain 5HT (Bakheit et al., 1992; Dinan et al., 1997; Sharpe et al., 1997), $5 \mathrm{HT}_{1 A}$ desensitization throughout the limbic system (Cleare et al., 2005), and numerous symptoms indicative of an inability to 
control the many functions modulated by 5HT (e.g., fatigue, proprioception, dyspnea, sensory sensitivity, dysautonomia, hypothyroidism, glucose control, immune function). Many signs, symptoms and anomalies of ME/CFS have been linked to $5 \mathrm{HT}$ (and downstream mediators), but studies involving SSRIs require cautious interpretation as these drugs initially increase extracellular $5 \mathrm{HT}$, before activating the $5 \mathrm{HT}_{1 \mathrm{~A}}$ autoreceptors to decrease 5HT and induce effect (Andrews et al., 2015). Thus, the authors hypothesize that ME/CFS results from CRFR2 upregulations in specific neurons of the raphé nuclei and limbic system, leading to a loss of homeostatic control over the functions mediated by those neurons.

\section{Therapeutic Approach}

If upregulated CRFR2 causes ME/CFS, the resulting inability to maintain homeostasis under dynamic threat cannot be repaired by static approaches (e.g., fixed-doses of CRF/5HT antibodies, CRFR2 antagonists or GABA agonists). This leaves CRFR2 downregulation as the most reasonable approach.

In vivo, subcutaneous CT38s, a short-lived CRFR2-selective agonist with no known off-target activity (Supplementary Material), induces dose-dependent changes in norepinephrine and corticosterone release, spontaneous movement (possibly motor effect), gastrointestinal transit, urine volume, respiratory minute volume, core body temperature, heart rate (HR) and mean arterial pressure (MAP) (Supplementary Figures 1A-I). That is, CRFR2 stimulation in healthy rats produces signs analogous to complaints of ME/CFS. These data also suggest that CT38s enters the central nervous system as: norepinephrine/corticosterone involve the hypothalamus (Dedic et al., 2018; Deussing and Chen, 2018; Godoy et al., 2018); respiration and core body temperature involve 5HT in the medullary respiratory neurons (Hilaire et al., 2010) and preoptic area of the anterior hypothalamus (Lin et al., 1998; Boulant, 2000), and consistent with CRFR2 stimulation elevating 5HT to decrease respiratory function and temperature (Supplementary Figures 1F-G); and HR involves CRFR1 and CRFR2 in the BNST (Oliveira et al., 2015). Escalating doses cause the HR and MAP responses to peak and then decrease, notably at lower concentrations or exposures by infusion than by bolus (Supplementary Figures 2A-D). Since agonist-mediated receptor endocytosis increases with agonist concentration and the duration of stimulation (Markovic et al., 2008, 2011; Hauger et al., 2013), this apparent loss of HR and MAP sensitivity plausibly resulted from CRFR2 endocytosis in limbic neurons, occurring at lower concentrations by infusion due to the additive effect of time. Thus, the authors propose utilizing agonist-mediated CRFR2 endocytosis to treat ME/CFS.

\section{MATERIALS AND METHODS}

\section{InTiME}

InTiME Investigated the safety and efficacy of subcutaneouslydosed CT38s in ME/CFS patients. This open-label trial was conducted at the Bateman Horne Center, under a physiciansponsored investigational new drug application filed with the
United States Food and Drug Administration (FDA), registered at ClinicalTrials.gov (NCT03613129), approved by Aspire IRB, in compliance with the Declaration of Helsinki and Good Clinical Practice, with all patients providing informed consent.

\section{Aims}

InTiME sought to show that an acute dose of subcutaneous CT38s in ME/CFS patients, could safely induce sustained symptom improvement, determined by comparing symptoms (see below) in the 28-day pre-treatment assessment period and the 28-day post-treatment assessment period (Figure 2). CRFR2 expression in the raphé nuclei and limbic system is neuronally-specific and adapts in realtime so cannot be measured. However, the observation of dose-dependent effect would link CRFR2 with ME/CFS, as CT38 is CRFR2-selective and has no off-target activity. Sustained effect would suggest CRFR2 endocytosis had occurred, as CT38 does not persist in rats or healthy humans, evidenced by the rapid normalization of induced HR increases (Supplementary Material), which are CRFR1/CRFR2-mediated in the BNST (Oliveira et al., 2015).

\section{Patients}

InTiME included 18-60 year-old, male or female patients, meeting the Fukuda, Canadian and National Academy of Medicine criteria for ME/CFS, living between 3,500 and 5,500 feet above sea level (related to cardio-pulmonary exercise testing, CPET), with a stable state of illness in the prior 3 months, i.e., absence of active or uncontrolled co-morbidities including infections or depression. InTiME excluded patients with untreated endocrine diagnoses, tachycardia, severe hypotension, renal impairment, or who were taking anti-retrovirals, short-term antivirals/antibiotics, rituximab, or medications interfering with 5HT, norepinephrine, dopamine or cortisol.

\section{Intervention}

The drug substance, CT38s, is the acetate salt of CT38 (free base), a custom, 40-amino acid peptide. It is a potent CRFR2-selective agonist (EC50 nmol/\% of Emax: 17.1/100), with no known offtarget activity. The drug product was supplied in active (CT38s: $1 \mathrm{mg} / \mathrm{ml}$ ) and diluent (vehicle: $0.05 \mathrm{M}$ TRIS buffer, $0.67 \% \mathrm{NaCl}$ in sterile $\mathrm{H}_{2} \mathrm{O}$ for injection, USP, $\mathrm{pH}$ 7.5-7.7) vials, requiring on-site dilution. The drug was delivered subcutaneously via programmable syringe pump (McKinley ${ }^{\mathrm{TM}}$ T34) utilizing a soft cannula infusion set (Neria ${ }^{\mathrm{TM}}$ Soft 90). Pharmacokinetic (PK) data are expressed in terms of CT38. CT38s has been studied in animals and healthy human subjects in a prior Phase 1 clinical trial (Supplementary Material), but data is not publicly available as it is part of an ongoing drug development program.

\section{Dosing}

The acute dose was intended to reproduce the reduced HR sensitivity noted in healthy rats by infusion, where apparent endocytosis occurred at a total exposure (i.e., area under the plasma concentration-time curve or AUC) of $\sim 40 \mathrm{ng} \mathrm{h} / \mathrm{ml}$ and a plasma concentration of at least $\sim 1.50 \mathrm{ng} / \mathrm{ml}$, human equivalents of $7 \mathrm{ng} \mathrm{h/ml}$ and $1.40 \mathrm{ng} / \mathrm{ml}$, respectively 


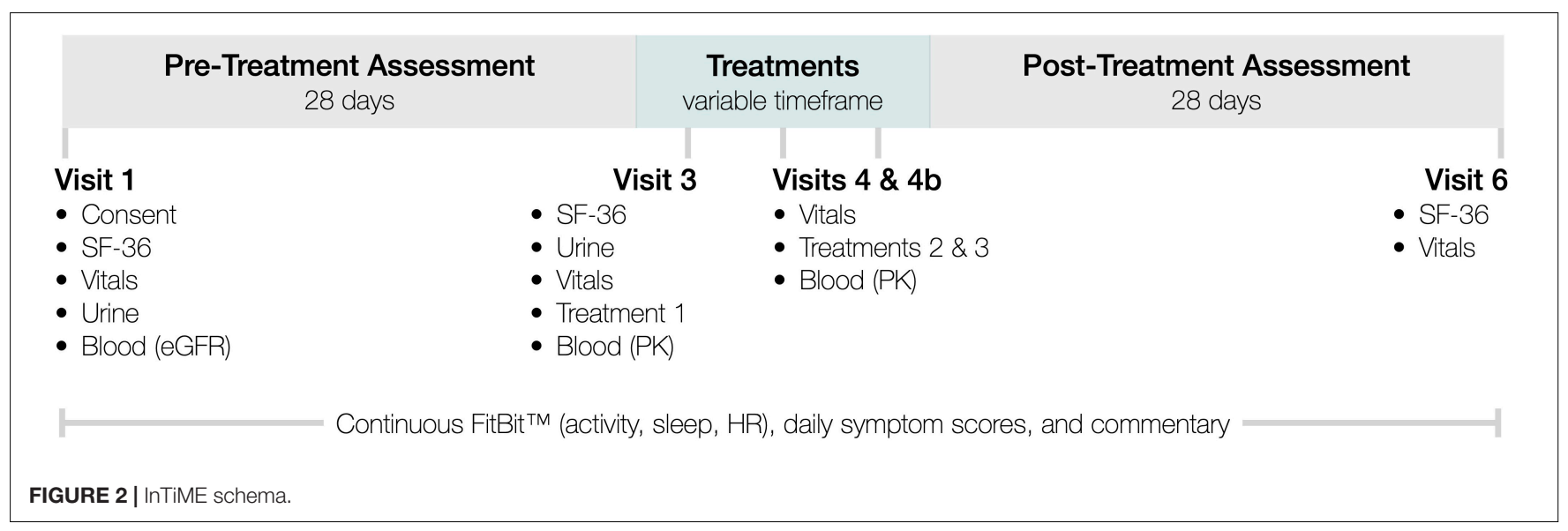

(Supplementary Figure 2). In an infusion, the maximum plasma concentration (Cmax) and AUC are governed by the rate and duration of infusion. Thus, the starting dose-level was planned as a 3 -h treatment, involving a priming bolus of $0.15 \mu \mathrm{g} / \mathrm{kg}$, and a continuous infusion at a rate (in $\mu \mathrm{g} / \mathrm{kg} / \mathrm{h}$ ) of 0.20 for $45 \mathrm{~min}$, escalating to 0.22 for $45 \mathrm{~min}$, then escalating to 0.24 for $90 \mathrm{~min}$-dose: $0.825 \mu \mathrm{g} / \mathrm{kg}$ (below the maximum tolerated bolus dose in the prior Phase 1 trial of $0.833 \mu \mathrm{g} / \mathrm{kg}$, Supplementary Material); projected Cmax: $1.37 \mathrm{ng} / \mathrm{ml}$ (below the maximum tolerated concentration of $1.56 \mathrm{ng} / \mathrm{ml}$ in the prior Phase 1 trial, Supplementary Material); projected AUC: $4.16 \mathrm{ng} \mathrm{h/ml}$. This was to be repeated at a second treatment to provide a total AUC of $8.33 \mathrm{ng} \mathrm{h} / \mathrm{ml}$. It was assumed that any achieved CRFR2 endocytosis would persist, so the number of treatments and their separation were not critical (generally planned as two treatments separated by at least two days, but varied due to dosing changes, see below). Assuming safety at this starting dose-level, InTiME planned two higher dose-levels in subsequent patients.

\section{Dosing Changes}

At the first treatment, the patient (ID24) experienced higher than anticipated hemodynamic changes. Since these changes were Cmax-related in rats and healthy subjects (Supplementary Material), the priming bolus and infusion rate escalations were eliminated, and the infusion duration increased to $3.5 \mathrm{~h}$ (referred to as D20, meaning $0.20 \mu \mathrm{g} / \mathrm{kg} / \mathrm{h}$ ), then utilized for ID24's second treatment and both of ID23's treatments. Both patients exhibited poor tolerability to D20. This necessitated reducing the dose-level to D03 $(0.03 \mu \mathrm{g} / \mathrm{kg} / \mathrm{h})$ to lower the Cmax and adding a third treatment to increase the total AUC. To characterize the doseresponse more fully, two additional dose-levels, D06 and D01, were also tested (Figure 3) - all approved by Aspire IRB.

\section{Blind Dose}

Though open-label, patients were unaware of their relative doses. The first two patients (D20) expected the lowest dose, but received the highest. The next three patients (D03) knew that for safety reasons their dose was lower than the first two patients. The remaining patients did not know their relative dose-levels, and these were not administered sequentially. Patients had no contact with one another.

\section{Outcomes}

The primary endpoint was the change in the mean total daily symptom score (TDSS), averaged over 28 days before the first treatment $\left(\right.$ TDSS $_{\text {pre }}$ ) and 28 days before exit from the trial $\left(\mathrm{TDSS}_{\text {post }}\right)$. The TDSS summed 13 individual symptoms (specifically, fatigue, muscle/joint pain, sleep issues, cognitive impairment, OI, abnormal temperature sensations, flu-like symptoms, headaches or sensory sensitivities, shortness of breath, gastrointestinal function, urogenital function, anxiety and depression), each patient-reported daily throughout the trial, on a $0-5$ scale $(0=$ none, $1=$ very mild, $2=$ mild, $3=$ moderate, $4=$ severe, and $5=$ very severe). The TDSS modifies the CFS Symptom Inventory (Wagner et al., 2005), expanding some symptoms (e.g., "sensory sensitivities" instead of "sensitivity to light"), collapsing others (e.g.,"abnormal temperature sensations" instead of "fever" and "chills") and utilizing a single 24-h score (instead of intensity and frequency, considered too cumbersome for daily use).

Secondary endpoints included: (i) general health, assessed via the 36-Item Short Form Survey Instrument (SF-36, 0-100 scale, $0=$ maximum disability, $100=$ no disability) (Ware et al., 1994), completed at enrollment, prior to the start of treatment, and at exit, each referencing the preceding 4 weeks; (ii) Fitbit ${ }^{\mathrm{TM}}$ metrics (activity, HR, and sleep), continuously monitored throughout the trial; and (iii) patient-reported daily assessments of: (a) completion of activities of daily living (ADL, $0=$ not at all, $1=$ a little, $2=$ some, $3=$ a lot, and 4 = completely); (b) avoidance of physical/mental exertion over PEM concerns (same as ADL scale); and (c) perceived level of physical/mental exertion in the prior $24 \mathrm{~h}$ (same as individual symptom scale). The original protocol included daily cognitive testing and CPET (both pre- and post-treatment). Both were eliminated, as the former showed evidence of patient learning before treatment, and the latter because seven patients had already undergone their post-treatment CPET before the third treatment was approved (i.e., after receiving only a fraction of the target AUC). 


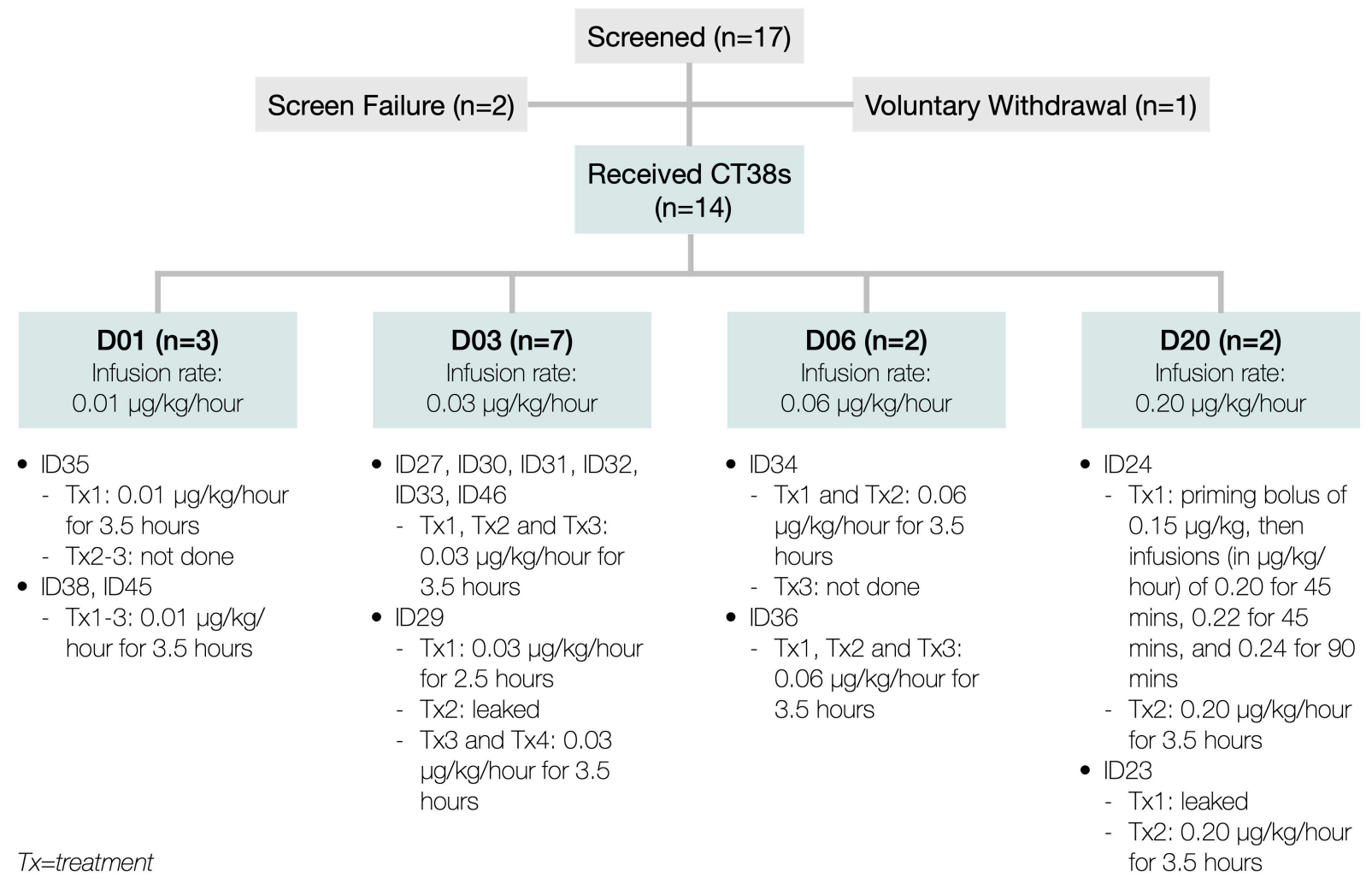

FIGURE 3 | Patient disposition.

Safety measures included a blood test at enrollment (for blood chemistry, complete blood count and estimated glomerular filtration rate), and urine tests at enrollment and before treatment (for illicit drugs and pregnancy). During treatment, HR, systolic (sBP) and diastolic ( $\mathrm{dBP}$ ) blood pressure were recorded just before dosing (baseline), every 15-min thereafter, and for at least $90 \mathrm{~min}$ post-treatment. Dosing was to be stopped in a given patient, if $\mathrm{HR}>120 \mathrm{bpm}$ (or $<45 \mathrm{bpm}$ ), sBP $<90 \mathrm{mmHg}$ or $\mathrm{dBP}<50 \mathrm{mmHg}$; or if $\mathrm{sBP}$ or $\mathrm{dBP}$ decreased by more than $20 \mathrm{mmHg}$ or $15 \mathrm{mmHg}$ from baseline on three consecutive readings, respectively. PK blood samples were obtained at intervals before, during and after treatment. The principal investigator (PI) and site staff were responsible for soliciting, recording and reporting events qualifying as adverse events (AEs) and serious adverse events (SAEs), which were followed until resolution/stabilization.

\section{Statistics}

InTiME was an exploratory study. All data are reported as mean and standard deviation, unless otherwise noted. Pre/post-treatment data were compared by Student's $t$-test. Relative sensitivity to CT38 among patients and healthy subjects were assessed by Kolmogorov-Smirnov test. Correlations were assessed by the Pearson product-moment correlation coefficient. No correction was applied for missing data, which was minimal (93.5\% compliance). Study data were collected and managed using REDCap ${ }^{\circledR}$ electronic data capture tools (Harris et al., 2009, 2019). Data collection was completed in April 2019.

\section{RESULTS}

\section{Patient Disposition}

Between July 2018 and April 2019, 17 patients were consented and enrolled. Of these, two were screen failures, one voluntarily withdrew, and 14 received CT38 treatment at one of four doselevels (Figure 3).

There were no study discontinuations. Two patients discontinued study drug, but remained in the study until exit: (i) ID35 (D01) received the first treatment, but experienced headache, facial numbness, body flushing, dyspnea, dizziness and swollen lymph nodes in the days following, so the PI decided to avoid further treatment; and (ii) ID34 (D06) received two treatments, but was noted to have poor venous access (necessary for blood sampling and safety, in the event of hypotension), so the PI decided to forego the third treatment.

There were three dose-related protocol deviations. ID23's first treatment and ID29's second treatment leaked at the cannula (observed by site staff and confirmed by PK). In addition, ID29's first treatment was only $2.5 \mathrm{~h}$ (daylight savings time error), so ID29 was given a fourth treatment. 
TABLE 1 | Patient demographics.

\begin{tabular}{|c|c|c|c|c|c|}
\hline & ALL & D01 & D03 & D06 & D20 \\
\hline$N$ & 14 & 3 & 7 & 2 & 2 \\
\hline Sex (Male/Female) & $6 / 8$ & $2 / 1$ & $2 / 5$ & $0 / 2$ & $2 / 0$ \\
\hline Race_White & 12 & 3 & 5 & 2 & 2 \\
\hline Race_Other & 2 & 0 & 2 & 0 & 0 \\
\hline Age (years) & $43.7 \pm 9.7$ & $46.0 \pm 8.2$ & $39.7 \pm 7.2$ & $53.6 \pm 0.6$ & $44.6 \pm 21.4$ \\
\hline Age_Onset (years) & $30.8 \pm 12.7$ & $31.0 \pm 15.1$ & $28.6 \pm 12.4$ & $41.5 \pm 9.2$ & $27.5 \pm 19.1$ \\
\hline Age_Diagnosis (years) & $34.6 \pm 12.3$ & $33.7 \pm 12.2$ & $32.4 \pm 10.4$ & $46.0 \pm 9.9$ & $32.5 \pm 24.7$ \\
\hline Onset (gradual/sudden) & $8 / 6$ & $2 / 1$ & $3 / 4$ & $1 / 1$ & $2 / 0$ \\
\hline \multicolumn{6}{|l|}{ Triggers } \\
\hline Infection & 13 & 3 & 6 & 2 & 2 \\
\hline Toxins & 4 & 1 & 2 & 0 & 1 \\
\hline Over-exertion & 2 & 0 & 1 & 1 & 0 \\
\hline Emotional & 4 & 0 & 3 & 0 & 1 \\
\hline
\end{tabular}

Age, Age_Onset and Age_Diagnosis indicate mean \pm standard deviation.

\section{Patient Demographics}

The trial population was reasonably represented in sex (six male, eight female), age (mean: 43.9 years, range: $29.4-59.7$ years), disease onset (eight gradual, six sudden), triggers (13 infectious, 4 toxins, 2 over-exertion, 4 emotional-some patients recorded multiple triggers), and disease duration (mean: 13.0 years, range: 2.1-25.0 years) (Table 1). Patients' symptoms were heterogeneous (with 6 of 13 individual symptoms indicated as the worst, and 11 indicated among the worst 3 ), and of mild to moderate severity (TDSS $_{\text {pre }}$ range: 13.8 to 44.7 , Table 2).

Actual CT38s dose varied due to changes in individual treatments (Figure 3) and drug preparation (which added a small drawn volume of active solution to a diluent). Thus, PK parameters were calculated for individual treatments, yielding mean Cmax and total AUC (Table 2).

\section{CRFR2 Sensitivity}

Relative to healthy subjects in the prior Phase 1 trial (Supplementary Material), ME/CFS patients were objectively more sensitive to the hemodynamic effects of CRFR2 stimulation during treatment. For a given CT38 concentration, the hemodynamic effects were greater in ME/CFS patients than in healthy subjects, and this differential diminished with increasing concentration, e.g., CT38 Cmax of 0.3 and $0.8 \mathrm{ng} / \mathrm{ml}$ result in mean HR increases in patients that are, respectively, $1.8 \times$ and $1.6 \times$ the corresponding change in healthy subjects

TABLE 2 | CT38s dose, pharmacokinetics, mean TDSS and activity, by patient.

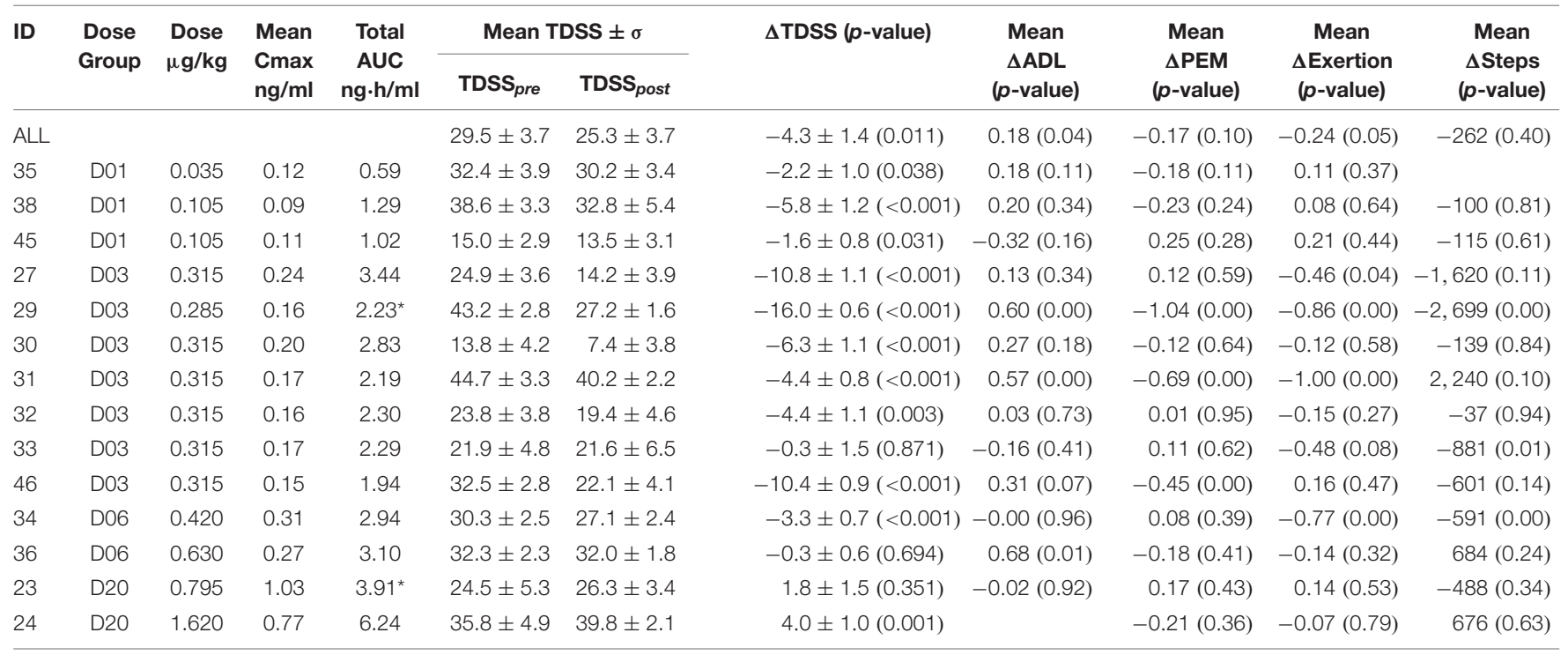

Mean Cmax averages across individual treatments; Total AUC sums individual treatments; $\Delta=$ pre-/post-treatment change in 28-day means of: total daily symptom score (TDSS); $A D L$ = the extent to which activities of daily living were completed; $P E M=$ the extent to which activities were avoided for fear of inducing PEM; Exertion = the perceived level of exertion; and Steps = Fitbit ${ }^{\mathrm{TM}}$-recorded level of activity (steps).

TDSS data indicated as mean \pm standard deviation.

*Ignores leaked treatment. 


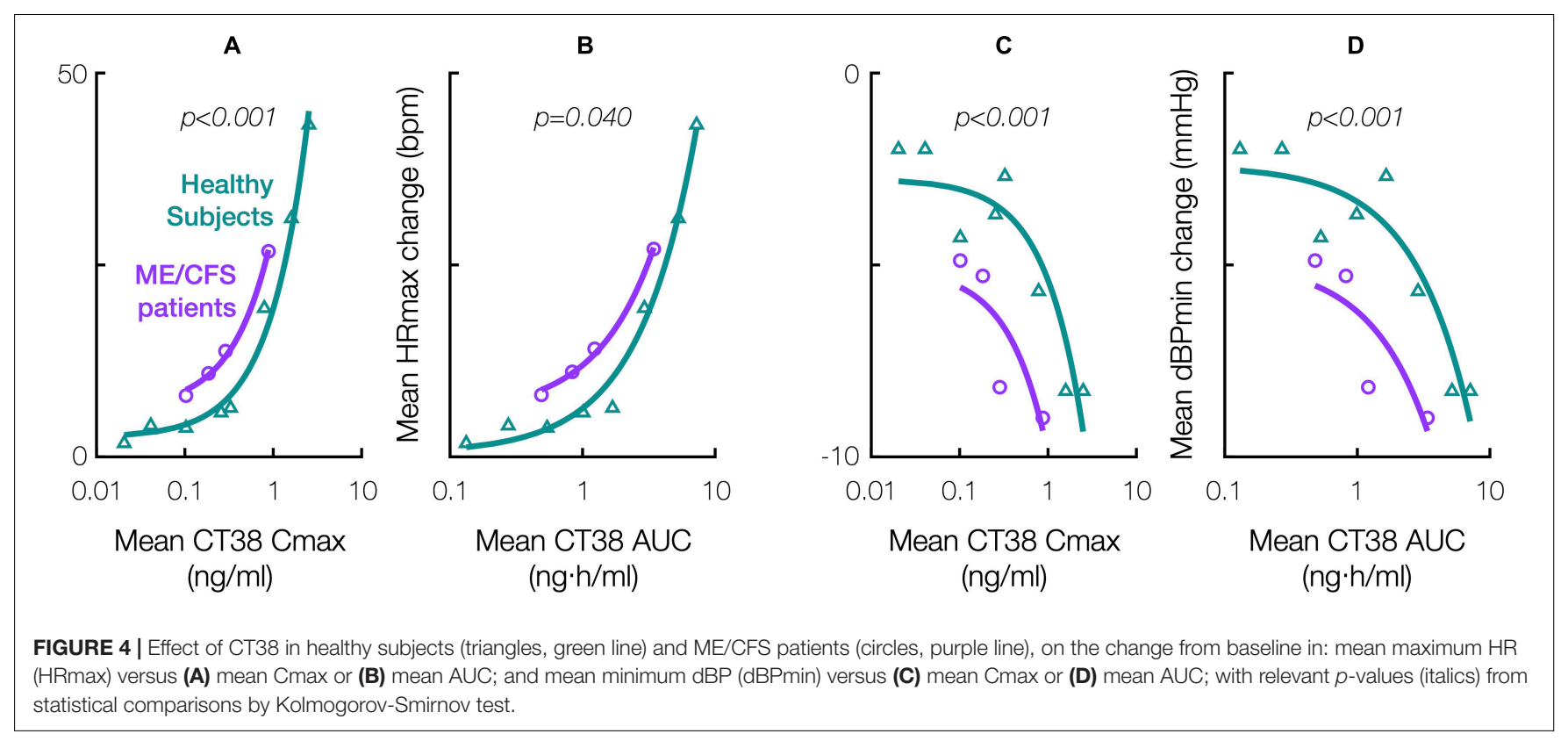

(Figures 4A-D). Hemodynamic sensitivity was significantly different between ME/CFS patients and healthy controls, with their cumulative distributions for maximum hemodynamic change (HR or $\mathrm{dBP}$ ) per unit of PK parameter (Cmax or AUC) differing between individual patient treatments ( $n=35$, InTiME) and individual healthy subject doses $(n=47$, prior Phase 1$)$ by Kolmogorov-Smirnov test (Figure 4).

\section{Efficacy}

\section{Intent-to-Treat Population}

CT38s was associated with a statistically significant improvement in mean TDSS TDSS $_{\text {pre: }} 29.5 \pm 3.7$, TDSS $_{\text {post }}: 25.3 \pm 3.7$, $p=0.011$, change: $-4.3 \pm 1.4$ or $-14.5 \%$ ) among all patients receiving drug (Table 2 ).

\section{Biphasic Dose-Response}

The pre-/post-treatment change in 28-day mean TDSS for individual patients was statistically significant in 11 of 14 patients (Figure 5). CT38 effect appeared to be biphasic, with symptoms improving at D01 and D03, but worsening at D20. At D06, symptoms were between D03 and D20. The AUC for ID27 (D03) exceeded that of ID34 and ID36 (D06), suggesting that this biphasic character might be driven by concentration rather than AUC.

Accordingly, stratifying for a Cmax threshold of $0.25 \mathrm{ng} / \mathrm{ml}$ (beyond which symptom improvement declined), the 28-day mean TDSS improved significantly for Cmax $<0.25 \mathrm{ng} / \mathrm{ml}$ $\left(n=10\right.$, TDSS $_{\text {pre }}: 29.1 \pm 3.6$, TDSS $_{\text {post }}: 22.9 \pm 4.1, p=0.003$, change: $-6.2 \pm 1.6$ or $-21.4 \%$ ), with all individual symptoms

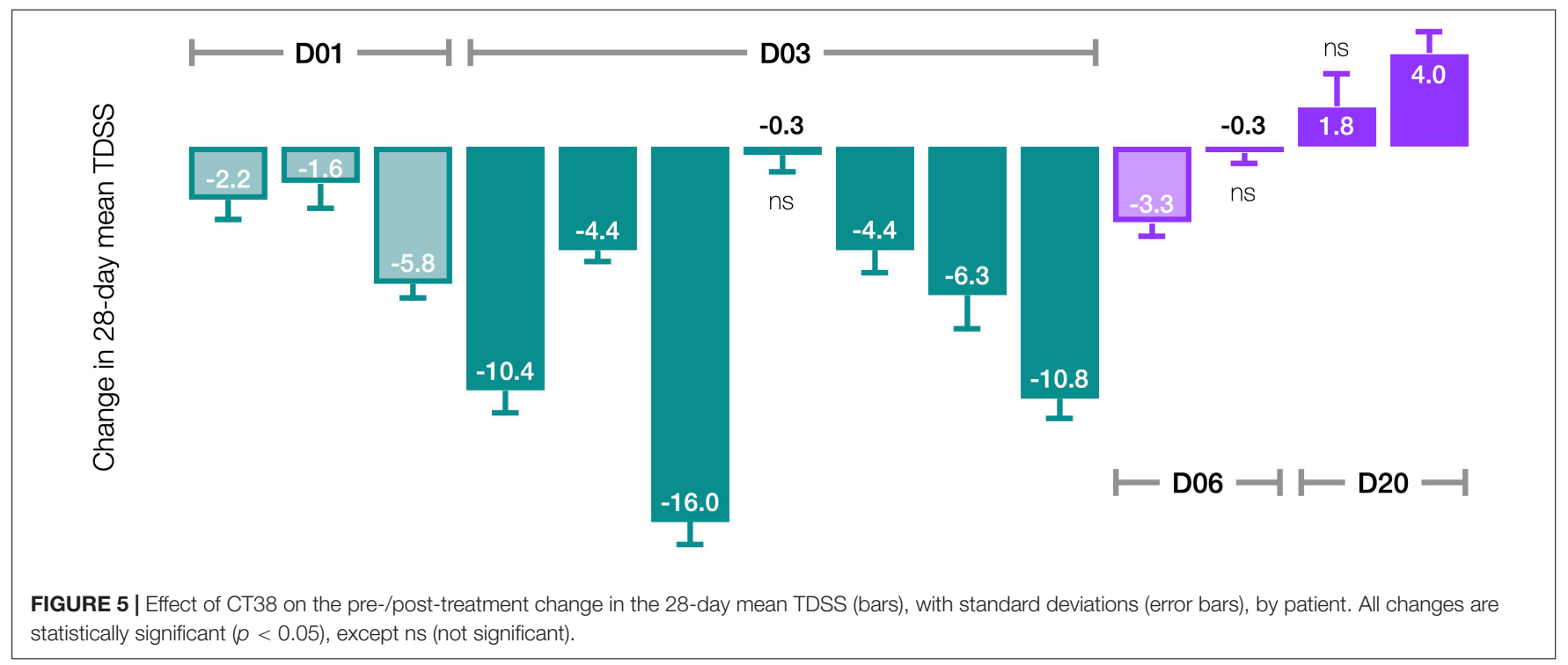




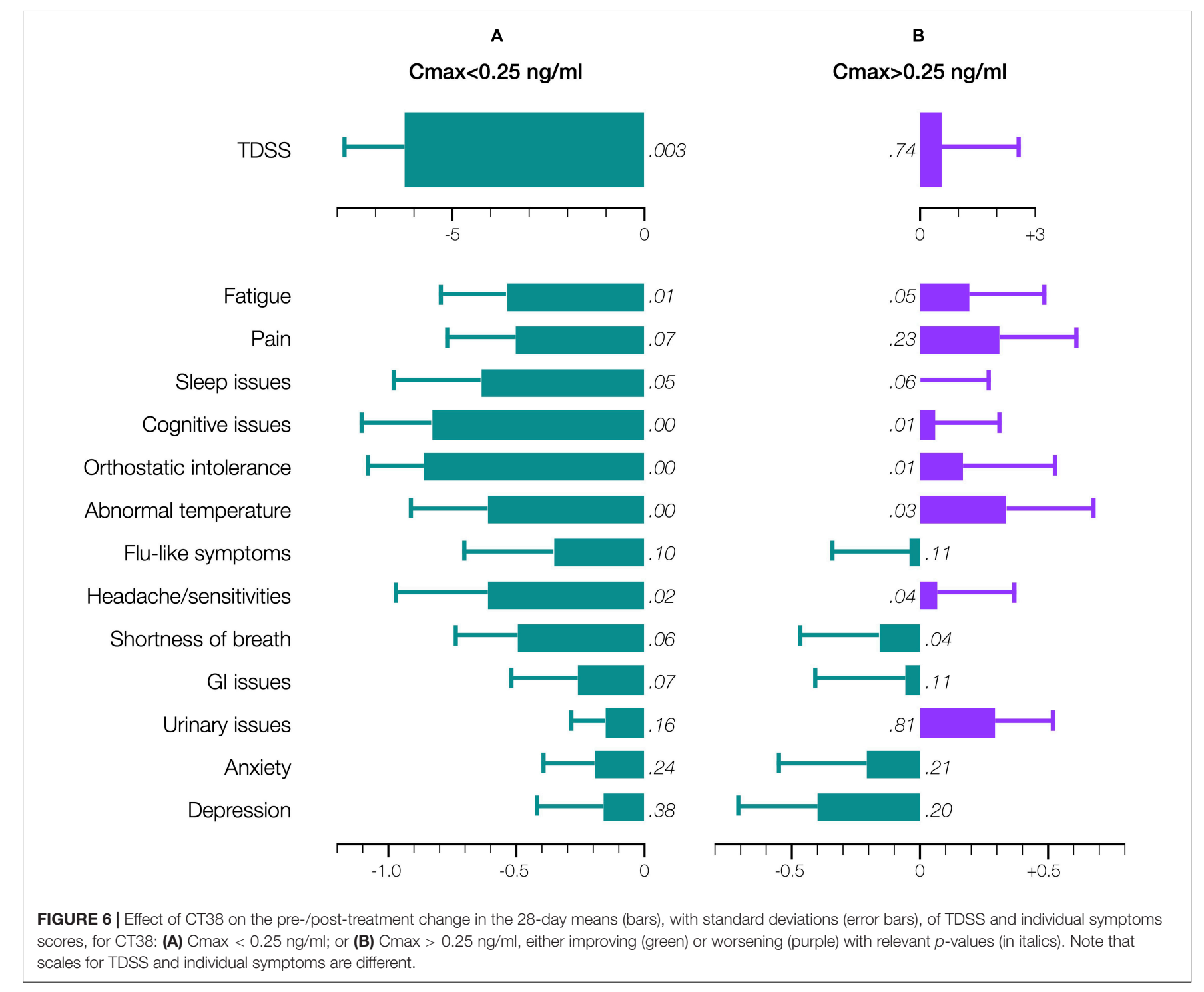

improving and several achieving significance (Figure 6A). The improvement in 28-day mean TDSS correlated directly with AUC and indirectly with pre-treatment symptom severity (Figure 7A, respective Pearson's correlation coefficients: -0.67 and -0.80 for patients with moderate symptoms, TDSS $_{\text {pre }}=32-45$, or mild symptoms, TDSS $_{\text {pre }}=14-25$ ). For $\mathrm{Cmax}>0.25 \mathrm{ng} / \mathrm{ml}$, the 28 day mean TDSS worsened though not significantly (Figure 6B, $n=4$, TDSS $_{\text {pre }}: 30.7 \pm 4.0$, TDSS $_{\text {post }}: 31.3 \pm 2.3, p=0.740$, change: $+0.6 \pm 2.0$ or $+1.8 \%$ ), but this lack of significance resulted from different AUCs, as there was a strong direct correlation between 28-day mean TDSS change and AUC (Figure 7B, Pearson's correlation coefficient: +0.88 ).

\section{SF-36}

Patients' pre-treatment, SF-36 physical (PCS: $27.9 \pm 4.0$ ) and mental (MCS: $34.0 \pm 3.6$ ) component scores indicated worse health status than patients with cancer, congestive heart failure or diabetes (respective US means PCS/MCS: 45.1/48.8,
31.0/45.7, and 39.3/47.9) (Ware et al., 1994). The 4-week pretreatment and pre-exit comparisons improved (significantly for PCS, $p=0.005$ ) for Cmax $<0.25 \mathrm{ng} / \mathrm{ml}$, but worsened for Cmax $>0.25 \mathrm{ng} / \mathrm{ml}$ (Figures 8A,B). Although not significant, results were substantially similar by TDSS and SF-36 (the latter being widely-validated though not in ME/CFS), so supporting the TDSS endpoint.

\section{Other Endpoints}

The effect of CT38s on activity was variable (Table 2). For Cmax $<0.25 \mathrm{ng} / \mathrm{ml}$, patients completed their ADL more (pre: $1.8 \pm 0.6$, post: $2.0 \pm 0.6, p=0.078$, change: $+0.2 \pm 0.3$ or $+10.0 \%)$ and avoided PEM-inducing activities less (pre: $2.2 \pm 0.7$, post: $2.0 \pm 0.6, p=0.115$, change: $-0.2 \pm 0.3$ or $-10.1 \%$ ), but were less active by patient-reported level of physical/mental exertion (pre: $2.4 \pm 0.8$, post: $2.2 \pm 0.7, p=0.099$, change: $-0.3 \pm 0.3$ or $-10.3 \%$ ) and Fitbit ${ }^{\mathrm{TM}}$-recorded steps (pre: 5,065 $\pm 2,675$, post: $4,670 \pm 2,246, p=0.351$, change: $-395 \pm 1,053$ or $-7.8 \%)$. 


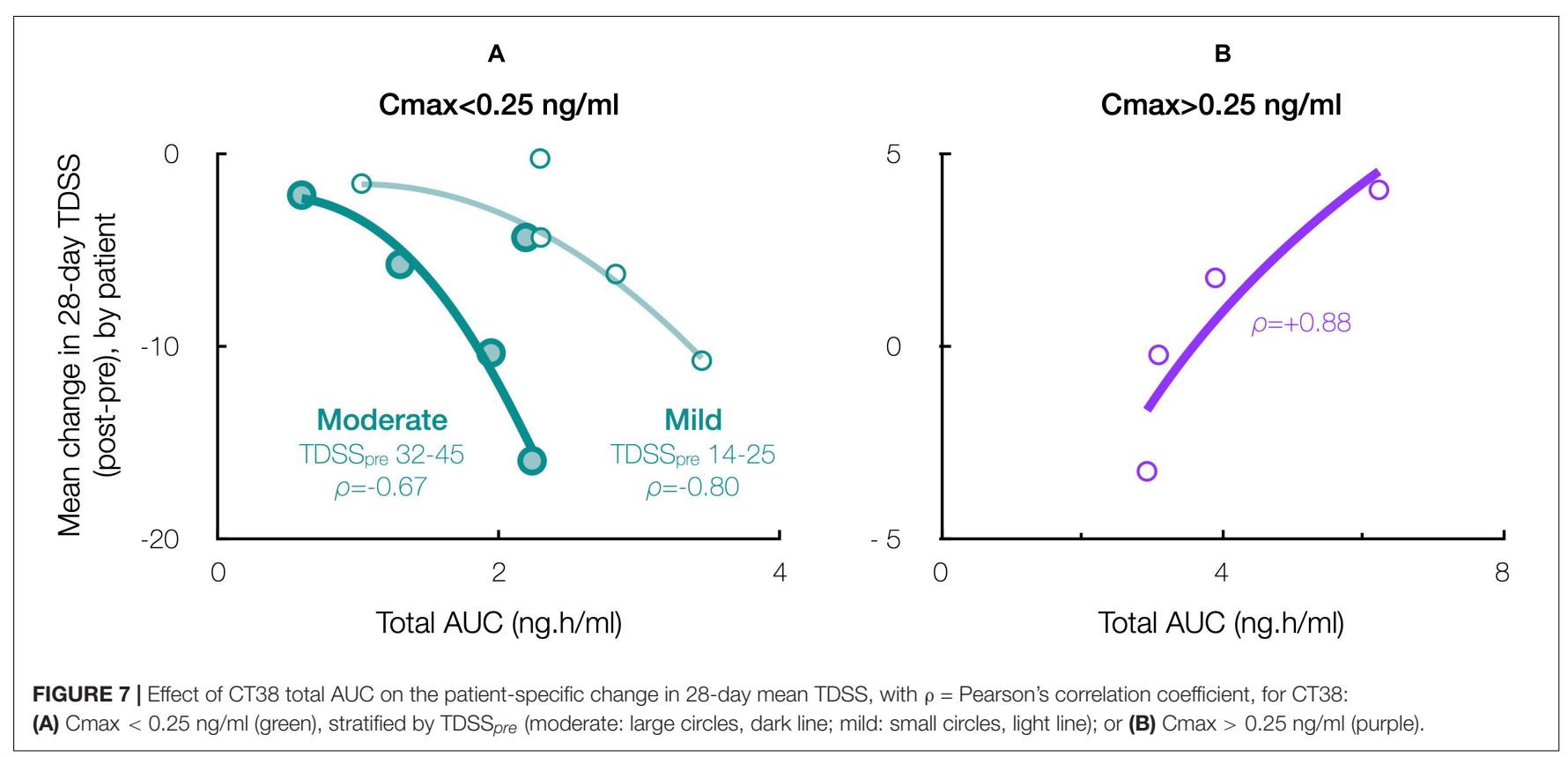

There was no correlation between patient-reported level of physical/mental exertion and Fitbit ${ }^{\mathrm{TM}}$ recorded steps (Pearson's correlation coefficient $=0.09$ for all patients).

Subgroup analysis for sex, age, illness duration, triggers and Fitbit ${ }^{\mathrm{TM}}$-recorded sleep and $\mathrm{HR}$ data, did not yield treatment-related insights, but this study was not powered to determine such effects.

\section{Safety}

There were no deaths. There was one study drug discontinuation (ID35, D01) due to symptom worsening (headache, facial numbness, dyspnea, dizziness and swollen lymph nodes) in the days following treatment, which did not require intervention.

There was one SAE during ID23's (D20) second treatment (first treatment leaked). The patient experienced tachycardia and hypotension (baseline: $92 \mathrm{bpm}, 108 / 74 \mathrm{mmHg}$; peak: $125 \mathrm{bpm}, 89 / 50 \mathrm{mmHg}$ ), recoded as two severe treatmentemergent AEs (TEAEs). The patient required rescue saline, but recovered and remained in the trial until planned exit. The SAE was reported to the FDA and IRB. It resulted from a poor prediction of the starting dose (derived from healthy animals/humans without CRFR2 upregulation), and an inadvertent continuation of dosing after the dose-stopping criteria were met. The patient also recorded severe fatigue after each treatment, so four severe TEAEs in total.

There were 161 AEs, four occurring before treatment (headache in ID30, sleep issues in ID23, hypotension in ID31, abnormal EKG in ID38). Of the remaining 157 TEAEs, four were severe (2.5\% noted above), the rest being mild (124 or $79.0 \%$ ) or moderate (29 or $18.5 \%$ ) and resolving without intervention. Hemodynamic changes (Figure 4) and flushing during treatment, putatively CRFR2-induced vasodilation (Venkatasubramanian et al., 2013), accounted for 12 and 37 TEAEs, respectively.

\section{DISCUSSION}

InTiME is the first study to identify that a CRFR2-selective agonist may provide therapeutic benefit in ME/CFS patientsnine of 10 patients where Cmax did not exceed $0.25 \mathrm{ng} / \mathrm{ml}$, showed significant, sustained TDSS improvement ranging from -1.6 to -16.0 , dependent on both AUC and pre-treatment severity. This work hypothesizes that ME/CFS is caused by CRFR2 upregulation in the raphé nuclei and limbic system, observed in vivo (Waselus et al., 2009; Lebow et al., 2012; Wood et al., 2013), with symptoms explained by the known effects of CRFR2 activation on this subset of 5HT neurons (Waselus et al., 2005; Kirby et al., 2008; Lukkes et al., 2008). It proposes that since CRFR2 undergoes agonist-mediated endocytosis (Markovic et al., 2008, 2011; Reyes et al., 2008, 2014; Hauger et al., 2013), treatment with an agonist may downregulate membrane-bound CRFR2. The trial results support these ideas.

\section{Biphasic Dose-Response}

InTiME sought to invoke agonist-mediated CRFR2 endocytosis, which is considered protective against overstimulation and known to increase with agonist concentration and duration of stimulation (Markovic et al., 2008, 2011; Hauger et al., 2013). The sustained symptom improvement over at least 28 days, with a peptide whose half-life is $1.5 \mathrm{~h}$, suggests that endocytosis occurred, but surprisingly, only at low CT38 dose-levels (D01 and D03). Why might this be the case? The threat response is likely terminated by UCN1mediated CRFR2 endocytosis (Markovic et al., 2008, 2011; Hauger et al., 2013). Like other G protein-coupled receptors, CRFR2 endocytosis is mediated by $\beta$-arrestin, which was thought to be recruited by activated $G$ proteins, so requiring agonist concentrations above the threshold at which the particular agonist activates the $\mathrm{G}$ proteins. Recently, however, 


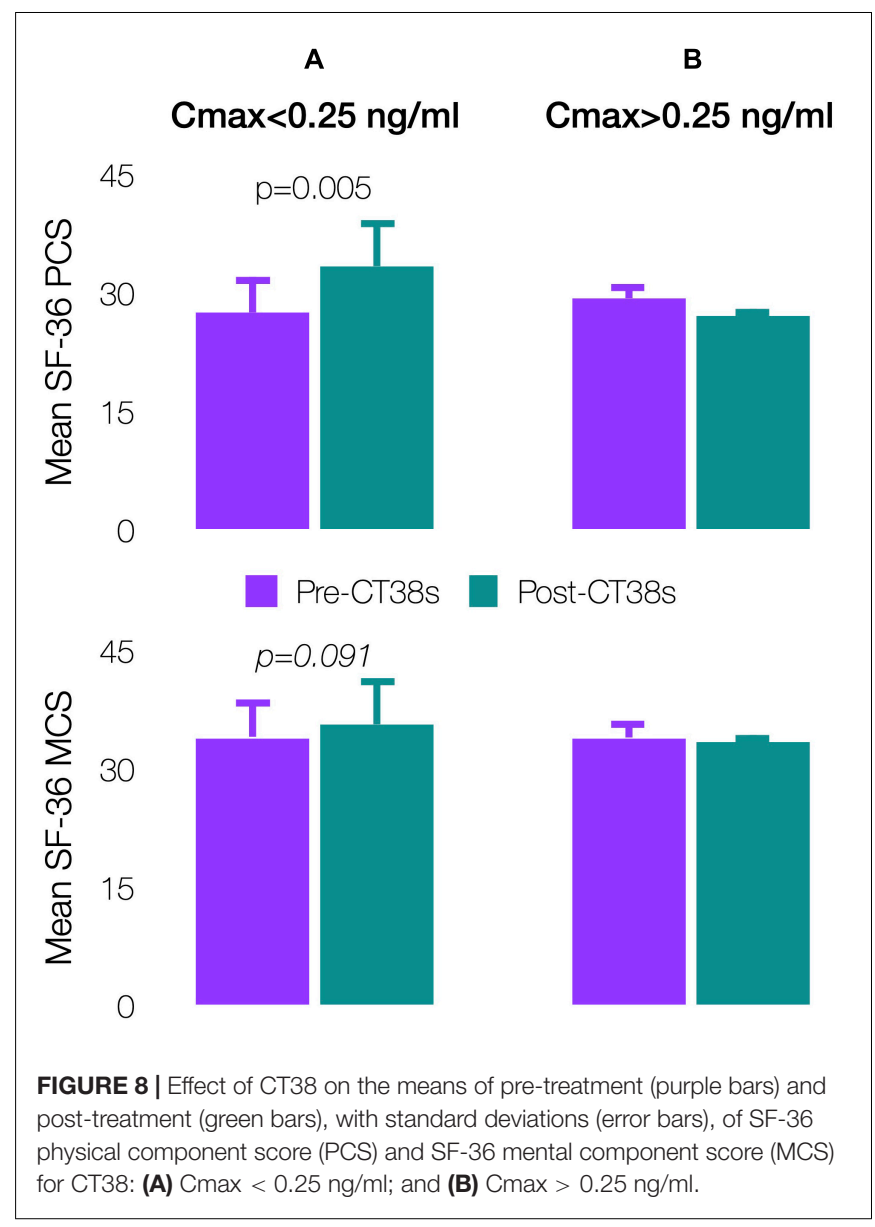

$\mathrm{G}$ protein-independent $\beta$-arrestin recruitment has been observed with another $G$ protein-coupled receptor (Pack et al., 2018), and may even accelerate $\beta$-arrestin recruitment (Markovic et al., 2011).

This notion may explain the biphasic dose-response. CT38 displaces CRF (respective CRFR2 binding affinities: 1.1 and $44.5 \mathrm{nmol}$ ), and activates $\mathrm{G}$ proteins at a threshold concentration of $\sim 0.25 \mathrm{ng} / \mathrm{ml}$, i.e., the lowest Cmax at which HR increased in healthy subjects in the prior Phase 1 trial (Figure $4 \mathbf{A}$ and Supplementary Material). Thus, for mean Cmax $<0.25 \mathrm{ng} / \mathrm{ml}$ (D01 and D03), G proteins did not activate, and symptom improvement (Figure 5) likely resulted from $G$ proteinindependent CRFR2 endocytosis, as effect was: (i) sustained long after drug clearance; (ii) AUC-dependent, consistent with endocytosis preventing overstimulation (Figure 7A); and (iii) indirectly dependent on symptom severity, also consistent with overstimulation, since if CRFR2 drives symptoms, then mild patients with only mild CRFR2 stimulation, will require relatively more treatment to achieve CRFR2 overstimulation (Figure 7A). For mean Cmax $>0.25 \mathrm{ng} / \mathrm{ml}$, G proteins activated during treatment (early for D20; late for D06), and sustained symptom worsening (Figure 5) suggests CRFR2 upregulation (Figure 7B), arguably demonstrating PEM (Figure 6B). These data suggest that overstimulation, and resulting endocytosis, can be achieved by extended durations at concentrations below the stimulatory threshold.

\section{Total Dose}

InTiME tested whether an acute CT38 exposure could have a sustained effect. Tolerability and symptom worsening at concentrations above $0.25 \mathrm{ng} / \mathrm{ml}$ necessitated a reduced infusion rate, so limiting the AUC that could be delivered in the allotted timeframes. However, provided Cmax remained below $0.25 \mathrm{ng} / \mathrm{ml}$, safety concerns were absent, and thus longer/additional infusions, to bring exposure closer to target (respectively, 3.7 and $4.9 \mathrm{ng} \mathrm{h/ml}$ for moderate and mild symptoms by extrapolation, Figure 7A), should increase efficacy. This point is evident in five patients (D03), who received 3-4 treatments sufficiently-separated to assess the effect of each treatment (Figure 9), resulting in mean TDSS decreases following treatments 1 and 2 combined (too close to separate), 3 and 4 (ID29). Overall, the see data support the notion that the AUC can be delivered as a single or multiple treatments, and increasing AUC increases effect.

\section{CRFR2 Sensitivity}

This is the first demonstration that the CRFR2 pathway is sensitized in ME/CFS patients, so consistent with the hypothesis. As noted above, CT38 plasma concentrations below $0.25 \mathrm{ng} / \mathrm{ml}$ do not activate $G$ proteins in healthy subjects, and thus the elevated hemodynamic response that occurred below $0.25 \mathrm{ng} / \mathrm{ml}$ in $\mathrm{ME} / \mathrm{CFS}$ patients (Figures $\mathbf{4 A}, \mathbf{C}$ ), likely represents elevated constitutive (agonist-independent) activity, putatively due to increased receptor expression (Black et al., 2016; Berg and Clarke, 2018). This increased sensitivity to low-level CRFR2 stimulation may aid diagnosis.

\section{TEAEs Versus Symptoms}

As CT38s is CRFR2-selective and has no off-target activity, the TEAEs resulted from CRFR2 stimulation. They included fatigue, myalgia, aches, sleep disturbance, forgetfulness, cognitive disturbance, dizziness, dysequilibrium, chills, influenza-like illness, sore throat, swollen lymph nodes, headache, paresthesia, shortness of breath, constipation, diarrhea, anxiety, emotional liability, etc. (and headache, dyspnea, sore throat and pain, in healthy subjects in the Phase 1, Supplementary Material). Such TEAEs are also known symptoms of ME/CFS. In fact, of the 108 TEAEs (excluding treatment day hemodynamics and flushing), 92 were well recognized ME/CFS symptoms and can be classified under the headings used in the TDSS endpoint (Table 3). This overlap of ME/CFS symptoms and TEAEs resulting from CRFR2 stimulation, including those in healthy subjects, supports the involvement of CRFR2 in ME/CFS.

The highest InTiME dose (D20: 0.795-1.620 $\mu \mathrm{g} / \mathrm{kg}$, Cmax $=1.15-1.32 \mathrm{ng} / \mathrm{ml}$, AUC $=3.91-9.85 \mathrm{ng} \mathrm{h} / \mathrm{ml}$ ) was associated with sustained effects (e.g., headache, dyspnea) in ME/CFS patients that were transient at a comparable dose in the Phase 1 healthy subjects $(1.667 \mu \mathrm{g} / \mathrm{kg}, \mathrm{Cmax}=2.46 \mathrm{ng} / \mathrm{ml}$, $\mathrm{AUC}=7.11 \mathrm{ng} \mathrm{h} / \mathrm{ml}$, Supplementary Material). That is, where healthy subjects reversed the effects of high-dose CT38s administration, ME/CFS patients did not, suggesting an impaired 


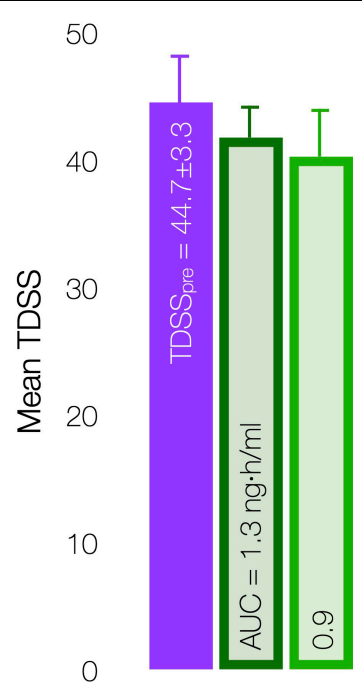

ID31

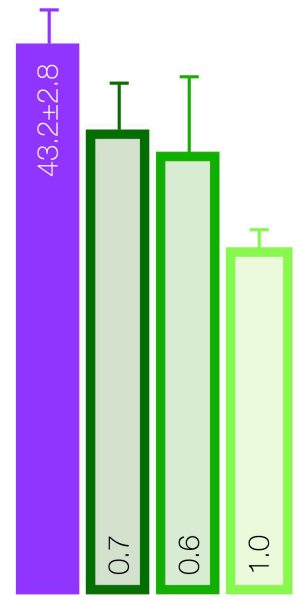

ID29

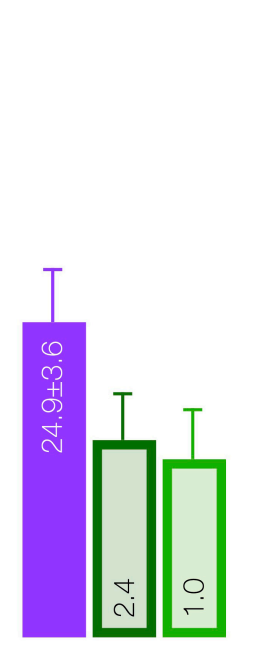

ID27

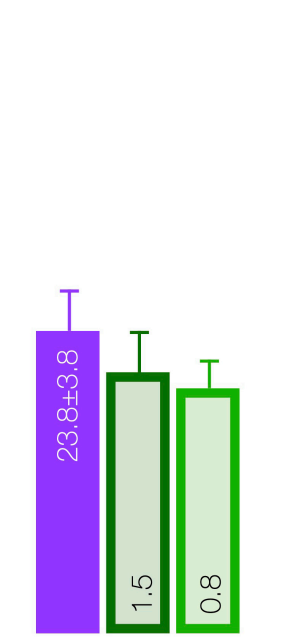

ID32
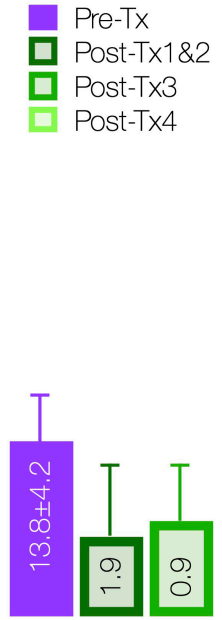

ID30

FIGURE 9 | Effect of CT38 individual treatment AUC on mean TDSS pre-treatment (purple bar) and post successive treatments (green bars), with standard deviations (error bars) and the level of AUC delivered in each successive treatment, by patient.

ability to reverse the effects of intense CRFR2 stimulation and therefore a susceptibility to CRFR2 maladaptation.

\section{Long-Term Data}

InTiME showed at least 28-day effect with a drug that clears in hours. Long-term follow-up in nine (of 14) patients, who are the PI's patients (with medical chart history), show that the effects are holding over a year from treatment (close to 2 years in the earlier-treated patients). Patients noted subtle improvements in sleep, brain fog, appetite, activity and PEM (crashed less often, recovered more rapidly, but it took weeks to appreciate these changes). While anecdotal, these data support the hypothesis/treatment approach.

\section{Disease Pathway}

In vivo, threat-specific CRFR2 upregulations in the raphé nuclei (Lukkes et al., 2008; Waselus et al., 2009; Wood et al., 2013) and limbic system (Sananbenesi et al., 2003; Lebow et al., 2012; Elharrar et al., 2013; Qi et al., 2014) have been shown to modulate limbic 5HT, and these upregulations can persist long after threat resolution. Consistent with this, high-dose CT38 modulates functions known to be mediated by limbic 5HT in healthy rats (Supplementary Figure 1), including norepinephrine/corticosterone release (Dedic et al., 2018; Deussing and Chen, 2018; Godoy et al., 2018), spontaneous movement, possibly motor effect (Perrier et al., 2013; Perrier and Cotel, 2015), breathing (Hilaire et al., 2010), thermoregulation (Lin et al., 1998; Boulant, 2000), and HR (Oliveira et al., 2015). CT38 modulates these same functions in ME/CFS patients, exacerbating them for $\mathrm{Cmax}>0.25 \mathrm{ng} / \mathrm{ml}$ while improving them for $\mathrm{Cmax}<0.25 \mathrm{ng} / \mathrm{ml}$, respectively, consistent with CRFR2 upregulation and endocytosis (Figure 6). This parallelism potentially positions CRFR2 in the raphé nuclei and limbic system as a pathway that responds to various environmental threats, e.g., pathogens, physical/mental trauma, chemicals, toxins (Table 1; Kerr and Mattey, 2008; Devendorf et al., 2016; Chu et al., 2019), upregulating in threat-relevant neurons (Devendorf et al., 2016), in a manner affected by prior threats/upregulations (Heim et al., 2006; Nater et al., 2011). CRFR2 can fail to downregulate, influenced by defects in threat response-related genes (Goertzel et al., 2006) and female sex (Bangasser et al., 2010, 2013; Bangasser, 2013; Howerton et al., 2014; Weathington et al., 2014; Lukkes et al., 2016), effectively changing the homeostatic set point, leading to 5HT deregulation, lost homeostasis, and the persistent signs and symptoms of ME/CFS. If validated, this pathway has several implications.

First, if CRFR1/CRFR2 are pivotal in homeostasis as proposed, the very nature of homeostatic threat dictates that CRFR1/CRFR2 adaptations are neuronally-specific, and thus maladaptations are also neuronally-specific. This ties individual signs/symptoms to specific neurons, e.g., CRFR2-induced 5HT elevations in the motor pathway could inhibit motor neuron firing (Perrier et al., 2013; Perrier and Cotel, 2015) manifesting as fatigue (Supplementary Figures 1B,C), while CRFR2-induced 5HT elevations in medullary respiratory neurons (Hilaire et al., 2010) could diminish breathing capacity (Supplementary Figure 1F). This may explain how the same symptom can present in different diseases (e.g., fatigue in ME/CFS, fibromyalgia, multiple sclerosis), and how symptoms can vary within a given disease.

Second, for limbic response to be precise, neuronal CRFR1/CRFR2 expression can only depend on the threat and its resolution. This suggests the absence of other influences on receptor levels, and thus treatment-induced CRFR2 endocytosis (mimicking threat resolution) should persist, thereby removing the impetus for elevated 5HT and allowing the $5 \mathrm{HT}_{1 A}$ autoreceptors to normalize and properly inhibit 5HT. Importantly, such endocytosis does not alter the adaptive nature 
TABLE 3 | Treatment-emergent adverse events, stratified by Cmax.

\begin{tabular}{|c|c|c|c|c|c|c|}
\hline & \multicolumn{2}{|c|}{ Cmax $<0.25 \mathrm{ng} / \mathrm{ml}(T=29)$} & \multicolumn{3}{|c|}{ Cmax $>0.25 \mathrm{ng} / \mathrm{ml}(T=9)$} & \multirow[t]{2}{*}{ Total } \\
\hline & Mild & Moderate & Mild & Moderate & Severe & \\
\hline Total & 99 & 12 & 25 & 17 & 4 & 157 \\
\hline \multicolumn{7}{|l|}{$\begin{array}{l}\text { During } \\
\text { Treatment }\end{array}$} \\
\hline Flushing & 27 & 1 & 3 & 6 & & 37 \\
\hline Cardiovascular & 4 & 1 & 4 & 1 & 2 & 12 \\
\hline \multicolumn{7}{|l|}{$\begin{array}{l}\text { TDSS-like } \\
\text { TEAEs }\end{array}$} \\
\hline $\begin{array}{l}\text { Headaches or } \\
\text { sensitivities }\end{array}$ & 12 & 3 & 3 & 1 & & 19 \\
\hline Fatigue & 7 & & 3 & 2 & 2 & 14 \\
\hline $\begin{array}{l}\text { Flu-like } \\
\text { symptoms }\end{array}$ & 10 & 1 & 1 & 1 & & 13 \\
\hline $\begin{array}{l}\text { Temperature } \\
\text { sensations }\end{array}$ & 8 & 1 & 2 & & & 11 \\
\hline Gl symptoms & 4 & 2 & 3 & & & 9 \\
\hline Sleep issues & 6 & & & 1 & & 7 \\
\hline Ol symptoms & 4 & 1 & & 1 & & 6 \\
\hline $\begin{array}{l}\text { Muscle or } \\
\text { joint pain }\end{array}$ & 3 & & & 1 & & 4 \\
\hline $\begin{array}{l}\text { Cognitive } \\
\text { symptoms }\end{array}$ & 3 & & & & & 3 \\
\hline Dyspnea & 2 & 1 & & & & 3 \\
\hline Depression & & & & 2 & & 2 \\
\hline Anxiety & & & 1 & & & 1 \\
\hline \multicolumn{7}{|l|}{ Other } \\
\hline Cardiovascular & & 1 & 2 & 1 & & 4 \\
\hline Psychological & 3 & & 2 & & & 5 \\
\hline Neurological & 3 & & 1 & & & 4 \\
\hline Pain & 2 & & & & & 2 \\
\hline $\begin{array}{l}\text { Metabolism or } \\
\text { nutritional }\end{array}$ & 1 & & & & & 1 \\
\hline
\end{tabular}

Data indicate actual number of recorded events; $T$, total number of drug treatments, by group.

of the system; it only restores the set points, reducing the level of $5 \mathrm{HT}$ release for a given threat. Future threats will continue to modulate CRFR1/CRFR2, albeit releasing less 5HT, but nothing prevents future severe threats from provoking maladaptations that might accumulate and eventually cause dysfunction.

Third, many acquired chronic diseases (Kotas and Medzhitov, 2015; Furman et al., 2019), including ME/CFS (Nacul et al., 2020), have been theorized to involve lost homeostasis brought on by chronic low-grade inflammation, possibly arising from chronic infection, diet, gut dysbiosis, environment, etc., but explaining how such inflammation leads to specific symptoms is challenging. CRFR1/CRFR2 maladaptation offers an alternative explanation for lost homeostasis and specific symptoms. This pathway controls autonomic and endocrine function (Dedic et al., 2018; Deussing and Chen, 2018; Godoy et al., 2018), and CRFR2-selective agonists modulate metabolic activity in obesity models (Jamieson et al., 2011; Chen et al., 2013; Paruthiyil et al., 2018) and immune response in models of sepsis (Gonzalez-Rey et al., 2006a), Crohn's disease (Gonzalez-Rey et al., 2006b), rheumatoid arthritis (Gonzalez-Rey et al., 2007) and cancer (Argilés et al., 2008), suggesting that CRFR2 plays a fundamental role. By implication, CRFR2 maladaptation could induce widespread dysfunction.

Fourth, maladaptations in limbic CRFR1/CRFR2 have no direct sequelae in bodily fluids. This is important because symptoms in the absence of bodily fluid abnormalities often lead to psychiatric diagnoses (common in ME/CFS), when the problem could be CRFR2 maladaptation. Equally, peripheral abnormalities need not imply peripheral dysfunction, e.g., poor lung function by spirometry might be diagnosed and treated as lung obstruction, yet could result from CRFR2induced changes in respiratory rate and tidal volume (Supplementary Figure 1F). Thus, an understanding of this pathway could have important diagnostic and treatment implications.

Fifth, given the proposed connection between individual neurons and symptoms, and the overlap of triggers, signs/symptoms with those of ME/CFS, the authors postulate that the pathway and treatment approach may apply to post-acute sequelae of SARS-CoV-2, chronic Lyme disease, fibromyalgia, post-traumatic stress disorder and multiple chemical sensitivities.

In sum, the authors propose that the CRFR1/CRFR2-5HT pathway controls homeostasis and that its disruption leads to lost homeostasis. If validated, this could fundamentally alter current conceptions and treatment of many acquired chronic diseases.

\section{Limitations}

InTiME had several limitations. It was small $(n=14)$ and open-label as treatment causes flushing. Tolerability (mild at D06, severe at D20) limited 2 dosing groups, and necessitated CT38 concentration reductions that were only partially offset by longer infusions, so target AUCs were low relative to the target dose. The concentrations of interest were close to the PK limit of quantitation $(0.20 \mathrm{ng} / \mathrm{ml})$. TDSS is not a validated endpoint in ME/CFS.

\section{Conclusion}

This study hypothesizes that ME/CFS is caused by CRFR2 upregulation in the raphé nuclei and limbic system, and it tests agonist-mediated CRFR2 endocytosis as a novel treatment approach. The results support CRFR2 involvement in ME/CFS, and identify a treatment paradigm that is Cmaxlimited and both AUC- and severity-dependent, leading to sustained symptom improvement. The PK-dependence of this response argues against a chance effect. These findings warrant further study.

\section{DATA AVAILABILITY STATEMENT}

The datasets presented in this article are not publicly available because they are part of an ongoing submission to the United States FDA. Requests to access the datasets should be directed to GP, gpereira@corteneinc.com. 


\section{ETHICS STATEMENT}

The studies involving human participants were reviewed and approved by Aspire Institutional Review Board and Independent Investigational Review Board Inc. The patients/participants provided their written informed consent to participate in this study. The animal studies were reviewed and approved by P\&G's Institutional Animal Care and Use Committee and/or attending veterinarian in full compliance with the Animal Welfare Act.

\section{AUTHOR CONTRIBUTIONS}

GP conceived the hypothesis and treatment approach, and drafted the article. All authors developed the protocol. LB and HG served as the study PI and Medical Monitor, respectively. GP, HG, SC, and MC proposed dosing and changes thereto, which LB approved. LB, TM, and SV collected the data. MC and GP assembled and analyzed the data. All authors revised and approved the final version.

\section{REFERENCES}

Alonge, K. M., D’Alessio, D. A., and Schwartz, M. W. (2021). Brain control of blood glucose levels: implications for the pathogenesis of type 2 diabetes. Diabetologia 64, 5-14. doi: 10.1007/s00125-020-05293-3

Andrews, P. W., Bharwani, A., Lee, K. R., Fox, M., and Thomson, J. A. (2015). Is serotonin an upper or a downer? The evolution of the serotonergic system and its role in depression and the antidepressant response. Neurosci. Biobehav. Rev. 51, 164-188. doi: 10.1016/j.neubiorev.2015.01.018

Argilés, J. M., Figueras, M., Ametller, E., Fuster, G., Olivan, M., de Oliveira, C. C. F., et al. (2008). Effects of CRF2R agonist on tumor growth and cachexia in mice implanted with Lewis lung carcinoma cells. Muscle Nerve 37, 190-195. doi: 10.1002/mus.20899

Armstrong, C. W., McGregor, N. R., Lewis, D. P., Butt, H. L., and Gooley, P. R. (2015). Metabolic profiling reveals anomalous energy metabolism and oxidative stress pathways in chronic fatigue syndrome patients. Metabolomics 11, 1626-1639. doi: 10.1007/s11306-0150816-5

Avery, M. C., and Krichmar, J. L. (2017). Neuromodulatory systems and their interactions: a review of models, theories, and experiments. Front. Neural Circuits 11:108. doi: 10.3389/fncir.2017.00108

Bakheit, A. M., Behan, P. O., Dinan, T. G., Gray, C. E., and O'Keane, V. (1992). Possible upregulation of hypothalamic 5-hydroxytryptamine receptors in patients with postviral fatigue syndrome. BMJ 304, 1010-1012. doi: 10.1136/ bmj.304.6833.1010

Bangasser, D. A. (2013). Sex differences in stress-related receptors: "micro" differences with "macro" implications for mood and anxiety disorders. Biol. Sex Differ. 4:2. doi: 10.1186/2042-6410-4-2

Bangasser, D. A., Curtis, A., Reyes, B. A. S., Bethea, T. T., Parastatidis, I., Ischiropoulos, H., et al. (2010). Sex differences in corticotropin-releasing factor receptor signaling and trafficking: potential role in female vulnerability to stress-related psychopathology. Mol. Psychiatry 15, 896-904. doi: 10.1038/mp. 2010.66

Bangasser, D. A., Reyes, B. A. S., Piel, D., Garachh, V., Zhang, X.-Y., Plona, Z. M., et al. (2013). Increased vulnerability of the brain norepinephrine system of females to corticotropin-releasing factor overexpression. Mol. Psychiatry 18, 166-173. doi: 10.1038/mp.2012.24

Berg, K. A., and Clarke, W. P. (2018). Making sense of pharmacology: inverse agonism and functional selectivity. Int. J. Neuropsychopharmacol. 21, 962-977. doi: 10.1093/ijnp/pyy071

Berger, M., Gray, J. A., and Roth, B. L. (2009). The expanded biology of serotonin. Ann. Rev. Med. 60, 355-366. doi: 10.1146/annurev.med.60.042307.110802

\section{FUNDING}

This research was funded by Cortene Inc., which owns the rights to СT38.

\section{ACKNOWLEDGMENTS}

The authors thank Susan Wood (for discussions on CRFR2 internalization and critique of this article), Dominic J. D. Hughes (for statistical guidance), the patients, the staff of the Bateman Horne Center, and Carol Turner and Cortene's investors.

\section{SUPPLEMENTARY MATERIAL}

The Supplementary Material for this article can be found online at: https://www.frontiersin.org/articles/10.3389/fnsys. 2021.698240/full\#supplementary-material

Berthoud, H.-R., and Neuhuber, W. L. (2000). Functional and chemical anatomy of the afferent vagal system. Autonomic Neurosci. 85, 1-17. doi: 10.1016/S15660702(00)00215-0

Black, J. B., Premont, R. T., and Daaka, Y. (2016). Feedback regulation of G proteincoupled receptor signaling by GRKs and arrestins. Seminars Cell Dev. Biol. 50, 95-104. doi: 10.1016/j.semcdb.2015.12.015

Boneva, R. S., Lin, J.-M. S., and Unger, E. R. (2015). Early menopause and other gynecologic risk indicators for chronic fatigue syndrome in women. Menopause 22, 826-834. doi: 10.1097/GME.0000000000000411

Borish, L., Schmaling, K., DiClementi, J. D., Streib, J., Negri, J., and Jones, J. F. (1998). Chronic fatigue syndrome: Identification of distinct subgroups on the basis of allergy and psychologic variables. J. Allergy Clin. Immunol. 102, 222-230. doi: 10.1016/S0091-6749(98)70090-9

Boulant, J. A. (2000). Role of the preoptic-anterior hypothalamus in thermoregulation and fever. Clin. Infect. Dis. 31, S157-S161. doi: $10.1086 / 317521$

Chanes, L., and Barrett, L. F. (2016). Redefining the role of limbic areas in cortical processing. Trends Cogn. Sci. 20, 96-106. doi: 10.1016/j.tics.2015.11.005

Chang, W., Kanda, H., Ikeda, R., Ling, J., DeBerry, J. J., and Gu, J. G. (2016). Merkel disc is a serotonergic synapse in the epidermis for transmitting tactile signals in mammals. Proc. Natl. Acad. Sci. U.S.A. 113, E5491-E5500. doi: 10.1073/pnas. 1610176113

Charnay, Y., and Léger, L. (2010). Brain serotonergic circuitries. Dial. Clin. Neurosci. 12, 471-487. doi: 10.31887/DCNS.2010.12.4/ycharnay

Chen, P., Hover, C. V., Lindberg, D., and Li, C. (2013). Central urocortin 3 and type 2 corticotropin-releasing factor receptor in the regulation of energy homeostasis: critical involvement of the ventromedial hypothalamus. Front. Endocrinol. 3:180. doi: 10.3389/fendo.2012.00180

Chia, J. K. S., and Chia, A. Y. (2007). Chronic fatigue syndrome is associated with chronic enterovirus infection of the stomach. J. Clin. Pathol. 61, 43-48. doi: 10.1136/jcp.2007.050054

Chu, L., Valencia, I. J., Garvert, D. W., and Montoya, J. G. (2018). Deconstructing post-exertional malaise in myalgic encephalomyelitis/ chronic fatigue syndrome: a patient-centered, cross-sectional survey. PLoS One 13:e0197811. doi: 10.1371/journal.pone.0197811

Chu, L., Valencia, I. J., Garvert, D. W., and Montoya, J. G. (2019). Onset patterns and course of myalgic encephalomyelitis/chronic fatigue syndrome. Front. Pediatrics 7:12. doi: 10.3389/fped.2019.00012

Cleare, A. J., Messa, C., Rabiner, E. A., and Grasby, P. M. (2005). Brain 5HT1A receptor binding in chronic fatigue syndrome measured using positron emission tomography and [11C]WAY-100635. Biol. Psychiatry 57, 239-246. doi: 10.1016/j.biopsych.2004.10.031 
Dantzer, R. (2018). Neuroimmune interactions: from the brain to the immune system and vice versa. Physiol. Rev. 98, 477-504. doi: 10.1152/physrev.00039. 2016

Dedic, N., Chen, A., and Deussing, J. M. (2018). The CRF family of neuropeptides and their receptors - mediators of the central stress response. Curr. Mol. Pharmacol. 11, 4-31. doi: 10.2174/1874467210666170302104053

Delhaye, B. P., Long, K. H., and Bensmaia, S. J. (2018). "Neural basis of touch and proprioception in primate cortex," in Comprehensive Physiology, ed. D. M. Pollock (Hoboken, NJ: John Wiley \& Sons, Inc), 1575-1602. doi: 10.1002/cphy. c170033

Deussing, J. M., and Chen, A. (2018). The corticotropin-releasing factor family: physiology of the stress response. Physiol. Rev. 98, 2225-2286. doi: 10.1152/ physrev.00042.2017

Devendorf, A. R., Brown, A. A., and Jason, L. A. (2016). The role of infectious and stress-related onsets in myalgic encephalomyelitis and chronic fatigue syndrome symptomatology and functioning. DePaul Dis. 5:6.

Dinan, T. G., Majeed, T., Lavelle, E., Scott, L. V., Berti, C., and Behan, P. (1997). Blunted serotonin-mediated activation of the hypothalamic-pituitary-adrenal axis in chronic fatigue syndrome. Psychoneuroendocrinology 22, 261-267. doi: 10.1016/S0306-4530(97)00002-4

Donovan, M. H., and Tecott, L. H. (2013). Serotonin and the regulation of mammalian energy balance. Neuroend. Sci. 7:36. doi: 10.3389/fnins.2013.00036

Dos Santos, E. D., Da Silva, A. V., Da Silva, K. R. T., Haemmerle, C. A. S., Batagello, D. S., Da Silva, J. M., et al. (2015). The centrally projecting edinger-westphal nucleus-I: efferents in the rat brain. J. Chem. Neuroanatomy 68, 22-38. doi: 10.1016/j.jchemneu.2015.07.002

Elharrar, E., Warhaftig, G., Issler, O., Sztainberg, Y., Dikshtein, Y., Zahut, R., et al. (2013). Overexpression of corticotropin-releasing factor receptor type 2 in the bed nucleus of stria terminalis improves posttraumatic stress disorderlike symptoms in a model of incubation of fear. Biol. Psychiatry 74, 827-836. doi: 10.1016/j.biopsych.2013.05.039

Ferguson, J. M. (2001). SSRI antidepressant medications: adverse effects and tolerability. Prim. Care Companion J. Clin. Psychiatry 3, 22-27. doi: 10.4088/ pcc.v03n0105

Flak, J. N., Goforth, P. B., Dell'Orco, J., Sabatini, P. V., Li, C., Bozadjieva, N., et al. (2020). Ventromedial hypothalamic nucleus neuronal subset regulates blood glucose independently of insulin. J. Clin. Investigation 130, 2943-2952. doi: 10.1172/JCI134135

Furman, D., Campisi, J., Verdin, E., Carrera-Bastos, P., Targ, S., Franceschi, C., et al. (2019). Chronic inflammation in the etiology of disease across the life span. Nat. Med. 25, 1822-1832. doi: 10.1038/s41591-019-0675-0

Godoy, L. D., Rossignoli, M. T., Delfino-Pereira, P., Garcia-Cairasco, N., and de Lima Umeoka, E. H. (2018). A comprehensive overview on stress neurobiology: basic concepts and clinical implications. Front. Behav. Neurosci. 12:127. doi: 10.3389/fnbeh.2018.00127

Goertzel, B. N., Pennachin, C., de Souza Coelho, L., Gurbaxani, B., Maloney, E. M., and Jones, J. F. (2006). Combinations of single nucleotide polymorphisms in neuroendocrine effector and receptor genes predict chronic fatigue syndrome. Pharmacogenomics 7, 475-483. doi: 10.2217/14622416.7.3.475

Gonzalez-Rey, E., Chorny, A., Varela, N., O'Valle, F., and Delgado, M. (2007). Therapeutic effect of urocortin on collagen-induced arthritis by downregulation of inflammatory and Th1 responses and induction of regulatory $\mathrm{T}$ cells. Arthr. Rheumatism 56, 531-543. doi: 10.1002/art.22394

Gonzalez-Rey, E., Chorny, A., Varela, N., Robledo, G., and Delgado, M. (2006a). Urocortin and adrenomedullin prevent lethal endotoxemia by down-regulating the inflammatory response. Am. J. Pathol. 168, 1921-1930. doi: 10.2353/ajpath. 2006.051104

Gonzalez-Rey, E., Fernandez-Martin, A., Chorny, A., and Delgado, M. (2006b). Therapeutic effect of urocortin and adrenomedullin in a murine model of Crohn's disease. Gut 55, 824-832. doi: 10.1136/gut.2005.084525

Harris, P. A., Taylor, R., Minor, B. L., Elliott, V., Fernandez, M., O’Neal, L., et al. (2019). The REDCap consortium: building an international community of software platform partners. J. Biomed. Inform. 95:103208. doi: 10.1016/j.jbi. 2019.103208

Harris, P. A., Taylor, R., Thielke, R., Payne, J., Gonzalez, N., and Conde, J. G. (2009). Research electronic data capture (REDCap)a metadata-driven methodology and workflow process for providing translational research informatics support. J. Biomed. Inform. 42, 377-381. doi: 10.1016/j.jbi.2008.08.010
Hauger, R. L., Olivares-Reyes, J. A., Braun, S., Hernandez-Aranda, J., Hudson, C. C., Gutknecht, E., et al. (2013). Desensitization of human CRF2(a) receptor signaling governed by agonist potency and Barrestin2 recruitment. Regul. Pept. 186, 62-76. doi: 10.1016/j.regpep.2013.06.009

Heath, T. P., Melichar, J. K., Nutt, D. J., and Donaldson, L. F. (2006). Human taste thresholds are modulated by serotonin and noradrenaline. J. Neurosci. 26, 12664-12671. doi: 10.1523/JNEUROSCI.3459-06.2006

Heim, C., Wagner, D., Maloney, E., Papanicolaou, D. A., Solomon, L., Jones, J. F., et al. (2006). Early adverse experience and risk for chronic fatigue syndrome: results from a population-based study. Arch. Gen. Psychiatry 63, 1258-1266. doi: $10.1001 /$ archpsyc.63.11.1258

Hensler, J. G. (2006). Serotonergic modulation of the limbic system. Neurosci. Biobehav. Rev. 30, 203-214. doi: 10.1016/j.neubiorev.2005. 06.007

Hilaire, G., Voituron, N., Menuet, C., Ichiyama, R. M., Subramanian, H. H., and Dutschmann, M. (2010). The role of serotonin in respiratory function and dysfunction. Res. Physiol. Neurobiol. 174, 76-88. doi: 10.1016/j.resp.2010.08. 017

Howerton, A. R., Roland, A. V., Fluharty, J. M., Marshall, A., Chen, A., Daniels, D., et al. (2014). Sex differences in corticotropin-releasing factor receptor-1 action within the dorsal raphe nucleus in stress responsivity. Biol. Psychiatry 75, 873-883. doi: 10.1016/j.biopsych.2013.10.013

Hurley, L. M., and Hall, I. C. (2011). Context-dependent modulation of auditory processing by serotonin. Hear. Res. 279, 74-84. doi: 10.1016/j.heares.2010.12. 015

Hvidberg, M. F., Brinth, L. S., Olesen, A. V., Petersen, K. D., and Ehlers, L. (2015). The health-related quality of life for patients with myalgic encephalomyelitis / chronic fatigue syndrome (ME/CFS). PLoS One 10:e0132421. doi: 10.1371/ journal.pone.0132421

Jamieson, P. M., Cleasby, M. E., Kuperman, Y., Morton, N. M., Kelly, P. A. T., Brownstein, D. G., et al. (2011). Urocortin 3 transgenic mice exhibit a metabolically favourable phenotype resisting obesity and hyperglycaemia on a high-fat diet. Diabetologia 54, 2392-2403. doi: 10.1007/s00125-011-22 05-6

Kerr, J. R., and Mattey, D. L. (2008). Preexisting psychological stress predicts acute and chronic fatigue and arthritis following symptomatic parvovirus B19 infection. Clin. Infect. Dis. 46, e83-e87. doi: 10.1086/533471

Kipnis, J. (2018). Immune system: the “seventh sense.”. J. Exp. Med. 215, 397-398. doi: 10.1084/jem.20172295

Kirby, L. G., Freeman-Daniels, E., Lemos, J. C., Nunan, J. D., Lamy, C., Akanwa, A., et al. (2008). Corticotropin-releasing factor increases GABA synaptic activity and induces inward current in 5-hydroxytryptamine dorsal raphe neurons. J. Neurosci. 28, 12927-12937. doi: 10.1523/JNEUROSCI.2887-08. 2008

Komaroff, A. L. (2019). Advances in understanding the pathophysiology of chronic fatigue syndrome. JAMA 322, 499-500. doi: 10.1001/jama.2019.8312

Kotas, M. E., and Medzhitov, R. (2015). Homeostasis, inflammation, and disease susceptibility. Cell 160, 816-827. doi: 10.1016/j.cell.2015.02.010

Lebow, M., Neufeld-Cohen, A., Kuperman, Y., Tsoory, M., Gil, S., and Chen, A. (2012). Susceptibility to PTSD-like behavior is mediated by corticotropinreleasing factor receptor type 2 levels in the bed nucleus of the stria terminalis. J. Neurosci. 32, 6906-6916. doi: 10.1523/JNEUROSCI.4012-11. 2012

Lin, M. T., Tsay, H. J., Su, W. H., and Chueh, F. Y. (1998). Changes in extracellular serotonin in rat hypothalamus affect thermoregulatory function. Am. J. Physiol. 274, R1260-R1267. doi: 10.1152/ajpregu.1998.274.5.R1260

Lukkes, J. L., Forster, G. L., Renner, K. J., and Summers, C. H. (2008). Corticotropin-releasing factor 1 and 2 receptors in the dorsal raphe differentially affect serotonin release in the nucleus accumbens. Eur. J. Pharmacol. 578, 185-193. doi: 10.1016/j.ejphar.2007.09.024

Lukkes, J. L., Norman, K. J., Meda, S., and Andersen, S. L. (2016). Sex differences in the ontogeny of CRF receptors during adolescent development in the dorsal raphe nucleus and ventral tegmental area: Ontogeny of CRF receptors in DR and VTA. Synapse 70, 125-132. doi: 10.1002/syn.21882

Lukkes, J. L., Summers, C. H., Scholl, J. L., Renner, K. J., and Forster, G. L. (2009). Early life social isolation alters corticotropin-releasing factor responses in adult rats. Neuroscience 158, 845-855. 10.1016/j.neuroscience.2008. 10.036 
Maloney, E. M., Boneva, R. S., Lin, J.-M. S., and Reeves, W. C. (2010). Chronic fatigue syndrome is associated with metabolic syndrome: results from a casecontrol study in Georgia. Metabolism 59, 1351-1357. doi: 10.1016/j.metabol. 2009.12.019

Markovic, D., Punn, A., Lehnert, H., and Grammatopoulos, D. K. (2008). Intracellular mechanisms regulating corticotropin-releasing hormone receptor$2 \beta$ endocytosis and interaction with extracellularly regulated kinase $1 / 2$ and p38 mitogen-activated protein kinase signaling cascades. Mol. Endocrinol. 22, 689-706. doi: 10.1210/me.2007-0136

Markovic, D., Punn, A., Lehnert, H., and Grammatopoulos, D. K. (2011). Molecular determinants and feedback circuits regulating type $2 \mathrm{CRH}$ receptor signal integration. Biochim. Biophys. Acta (BBA) Mol. Cell Res. 1813, 896-907. doi: 10.1016/j.bbamcr.2011.02.005

Morris, G., Berk, M., Galecki, P., and Maes, M. (2014). The emerging role of autoimmunity in myalgic encephalomyelitis/chronic fatigue syndrome (ME/cfs). Mol. Neurobiol. 49, 741-756. doi: 10.1007/s12035-0138553-0

Nacul, L., O’Boyle, S., Palla, L., Nacul, F. E., Mudie, K., Kingdon, C. C., et al. (2020). How myalgic encephalomyelitis/chronic fatigue syndrome (ME/CFS) progresses: the natural history of ME/CFS. Front. Neurol. 11:826. doi: 10.3389/ fneur.2020.00826

Nakatomi, Y., Mizuno, K., Ishii, A., Wada, Y., Tanaka, M., Tazawa, S., et al. (2014). Neuroinflammation in patients with chronic fatigue syndrome/myalgic encephalomyelitis: an 11C-(R)-PK11195 PET study. J. Nucl. Med. 55, 945-950. doi: 10.2967/jnumed.113.131045

Naschitz, J. E., Yeshurun, D., and Rosner, I. (2004). Dysautonomia in chronic fatigue syndrome: facts, hypotheses, implications. Med. Hypotheses 62, 203-206. doi: 10.1016/S0306-9877(03)00331- 1

Nater, U. M., Maloney, E., Heim, C., and Reeves, W. C. (2011). Cumulative life stress in chronic fatigue syndrome. Psychiatry Res. 189, 318-320. doi: 10.1016/j. psychres.2011.07.015

Neufeld-Cohen, A., Kelly, P. A. T., Paul, E. D., Carter, R. N., Skinner, E., Olverman, H. J., et al. (2012). Chronic activation of corticotropinreleasing factor type 2 receptors reveals a key role for 5-HT1A receptor responsiveness in mediating behavioral and serotonergic responses to stressful challenge. Biol. Psychiatry 72, 437-447. doi: 10.1016/j.biopsych.2012. 05.005

Newton, J. L., Okonkwo, O., Sutcliffe, K., Seth, A., Shin, J., and Jones, D. E. J. (2007). Symptoms of autonomic dysfunction in chronic fatigue syndrome. QJM 100 , 519-526. doi: 10.1093/qjmed/hcm057

Nicolson, G. L., Nasralla, M. Y., De Meirleir, K., and Haier, J. (2002). "Bacterial and viral co-infections in chronic fatigue syndrome (CFS/ME) patients," in Proceeding of the Clinical and Scientific Conference on Myalgic Encephalopathy/Chronic Fatigue Syndrome, 1-12.

Obara, N., Kamiya, H., and Fukuda, S. (2014). Serotonergic modulation of inhibitory synaptic transmission in mouse inferior colliculus. Biomed. Res. 35, 81-84. doi: 10.2220/biomedres.35.81

Oliveira, L. A., Almeida, J., Benini, R., and Crestani, C. C. (2015). CRF1 and CRF2 receptors in the bed nucleus of the stria terminalis modulate the cardiovascular responses to acute restraint stress in rats. Pharmacol. Res. 95-96, 53-62. doi: 10.1016/j.phrs.2015.03.012

Pack, T. F., Orlen, M. I., Ray, C., Peterson, S. M., and Caron, M. G. (2018). The dopamine D2 receptor can directly recruit and activate GRK2 without G protein activation. J. Biol. Chem. 293, 6161-6171. doi: 10.1074/jbc.RA117.001300

Paruthiyil, S., Hagiwara, S., Kundassery, K., and Bhargava, A. (2018). Sexually dimorphic metabolic responses mediated by CRF2 receptor during nutritional stress in mice. Biol. Sex Differ. 9:49. doi: 10.1186/s13293-0180208-4

Perrier, J.-F., and Cotel, F. (2015). Serotonergic modulation of spinal motor control. Curr. Opin. Neurobiol. 33, 1-7. doi: 10.1016/j.conb.2014.12.008

Perrier, J.-F., Rasmussen, H., Christensen, R., and Petersen, A. (2013). Modulation of the intrinsic properties of motoneurons by serotonin. CPD 19, 4371-4384. doi: 10.2174/13816128113199990341

Petzold, G. C., Hagiwara, A., and Murthy, V. N. (2009). Serotonergic modulation of odor input to the mammalian olfactory bulb. Nat. Neurosci. 12, 784-791. doi: $10.1038 / \mathrm{nn} .2335$
Pozo, M., and Claret, M. (2018). Hypothalamic control of systemic glucose homeostasis: the pancreas connection. Trends Endocrinol. Metabolism 29, 581594. doi: 10.1016/j.tem.2018.05.001

Qi, X., Shan, Z., Ji, Y., Guerra, V., Alexander, J. C., Ormerod, B. K., et al. (2014). Sustained AAV-mediated overexpression of CRF in the central amygdala diminishes the depressive-like state associated with nicotine withdrawal. Transl. Psychiatry 4:e385. doi: 10.1038/tp.2014.25

Quintanar, J. L., and Guzmán-Soto, I. (2013). Hypothalamic neurohormones and immune responses. Front. Integr. Neurosci. 7:56. doi: 10.3389/fnint.2013.00056

Reyes, B. A. S., Bangasser, D. A., Valentino, R. J., and Van Bockstaele, E. J. (2014). Using high resolution imaging to determine trafficking of corticotropinreleasing factor receptors in noradrenergic neurons of the rat locus coeruleus. Life Sci. 112, 2-9. doi: 10.1016/j.lfs.2014.07.017

Reyes, B. A. S., Valentino, R. J., and Van Bockstaele, E. J. (2008). Stress-induced intracellular trafficking of corticotropin-releasing factor receptors in rat locus coeruleus neurons. Endocrinology 149, 122-130. doi: 10.1210/en.2007-0705

Roh, E., Song, D. K., and Kim, M.-S. (2016). Emerging role of the brain in the homeostatic regulation of energy and glucose metabolism. Exp. Mol. Med. 48:e216. doi: 10.1038/emm.2016.4

Rozeske, R. R., Evans, A. K., Frank, M. G., Watkins, L. R., Lowry, C. A., and Maier, S. F. (2011). Uncontrollable, but not controllable, stress desensitizes 5HT1A receptors in the dorsal raphe nucleus. J. Neurosci. 31, 14107-14115. doi: 10.1523/JNEUROSCI.3095-11.2011

Ruiz-Núñez, B., Tarasse, R., Vogelaar, E. F., Janneke Dijck-Brouwer, D. A., and Muskiet, F. A. J. (2018). Higher prevalence of "low T3 syndrome" in patients with chronic fatigue syndrome: a case-control study. Front. Endocrinol. 9:97. doi: 10.3389/fendo.2018.00097

Sananbenesi, F., Fischer, A., Schrick, C., Spiess, J., and Radulovic, J. (2003). Mitogen-activated protein kinase signaling in the hippocampus and its modulation by corticotropin-releasing factor receptor 2: a possible link between stress and fear memory. J. Neurosci. 23, 11436-11443. doi: 10.1523/jneurosci. 23-36-11436.2003

Sharpe, M., Hawton, K., Clements, A., and Cowen, P. J. (1997). Increased brain serotonin function in men with chronic fatigue syndrome. BMJ 315, 164-165. doi: 10.1136/bmj.315.7101.164

Shimegi, S., Kimura, A., Sato, A., Aoyama, C., Mizuyama, R., Tsunoda, K., et al. (2016). Cholinergic and serotonergic modulation of visual information processing in monkey V1. J. Physiol. Paris 110, 44-51. doi: 10.1016/j.jphysparis. 2016.09.001

Silverman, M. N., Pearce, B. D., Biron, C. A., and Miller, A. H. (2005). Immune modulation of the hypothalamic-pituitary-adrenal (HPA) axis during viral infection. Viral. Immunol. 18, 41-78. doi: 10.1089/vim.2005. 18.41

Soto-Tinoco, E., Guerrero-Vargas, N. N., and Buijs, R. M. (2016). Interaction between the hypothalamus and the immune system: Hypothalamusimmune system interaction. Exp. Physiol. 101, 1463-1471. doi: 10.1113/EP08 5560

Straus, S., Dale, J., Wright, R., and Metcalfe, D. (1988). Allergy and the chronic fatigue syndrome. J. Allergy Clin. Immunol. 81, 791-795. doi: 10.1016/00916749(88)90933-5

Sundman, E., and Olofsson, P. S. (2014). Neural control of the immune system. Adv. Physiol. Educ. 38, 135-139. doi: 10.1152/advan.00094.2013

Tups, A., Benzler, J., Sergi, D., Ladyman, S. R., and Williams, L. M. (2017). “Central regulation of glucose homeostasis," in Comprehensive Physiology, ed. R. Terjung (Hoboken, NJ: John Wiley \& Sons, Inc), 741-764. doi: 10.1002/cphy.c160 015

van Campen, C. L. M. C., Rowe, P. C., Verheugt, F. W. A., and Visser, F. C. (2021). Numeric rating scales show prolonged post-exertional symptoms after orthostatic testing of adults with myalgic encephalomyelitis/chronic fatigue syndrome. Front. Med. 7:602894. doi: 10.3389/fmed.2020.602894

Venkatasubramanian, S., Griffiths, M. E., McLean, S. G., Miller, M. R., Luo, R., Lang, N. N., et al. (2013). Vascular effects of urocortins 2 and 3 in healthy volunteers. J. Am. Heart. Assoc. 2:e004267. doi: 10.1161/JAHA.112.004 267

Wagner, D., Nisenbaum, R., Heim, C., Jones, J. F., Unger, E. R., and Reeves, W. C. (2005). Psychometric properties of the CDC symptom inventory for assessment 
of chronic fatigue syndrome. Population Health Metrics 3:8. doi: 10.1186/14787954-3-8

Ware, J. E., Kosinski, M., and Keller, S. D. (1994). SF-36 Physical and Mental Health Summary Scales: A User's Manual. Available online at: https://books.google. com/books?id=UQDKDAEACAAJ.

Waselus, M., Nazzaro, C., Valentino, R. J., and Van Bockstaele, E. J. (2009). Stressinduced redistribution of corticotropin-releasing factor receptor subtypes in the dorsal raphe nucleus. Biol. Psychiatry 66, 76-83. doi: 10.1016/j.biopsych.2009. 02.014

Waselus, M., Valentino, R. J., and Van Bockstaele, E. J. (2005). Ultrastructural evidence for a role of $\gamma$-aminobutyric acid in mediating the effects of corticotropin-releasing factor on the rat dorsal raphe serotonin system. J. Comp. Neurol. 482, 155-165. doi: 10.1002/cne.20360

Waselus, M., Valentino, R. J., and Van Bockstaele, E. J. (2011). Collateralized dorsal raphe nucleus projections: a mechanism for the integration of diverse functions during stress. J. Chem. Neuroanat. 41, 266-280. doi: 10.1016/j.jchemneu.2011. 05.011

Weathington, J. M., Hamki, A., and Cooke, B. M. (2014). Sex- and region-specific pubertal maturation of the corticotropin-releasing factor receptor system in the rat: pubertal maturation of the forebrain crf. J. Comp. Neurol. 522, 1284-1298. doi: $10.1002 /$ cne.23475

Wood, S. K., Zhang, X.-Y., Reyes, B. A. S., Lee, C. S., Van Bockstaele, E. J., and Valentino, R. J. (2013). Cellular adaptations of dorsal raphe serotonin neurons associated with the development of active coping in response to social stress. Biol. Psychiatry 73, 1087-1094. doi: 10.1016/j.biopsych.2013. 01.026
Conflict of Interest: GP, HG, SC, MC, and LB are shareholders of Cortene Inc., which owns the commercial rights to the drug being tested.

The remaining authors declare that the research was conducted in the absence of any commercial or financial relationships that could be construed as a potential conflict of interest.

The authors declare that this study received funding from Cortene, Inc. The funder conceived of the idea to test CT38 in ME/CFS and was involved in the overall study design, protocol preparation, data analysis and writing the manuscript. The funder was not involved in recruiting patients, data collection or the conduct of the clinical trial.

Publisher's Note: All claims expressed in this article are solely those of the authors and do not necessarily represent those of their affiliated organizations, or those of the publisher, the editors and the reviewers. Any product that may be evaluated in this article, or claim that may be made by its manufacturer, is not guaranteed or endorsed by the publisher.

Copyright (C) 2021 Pereira, Gillies, Chanda, Corbett, Vernon, Milani and Bateman. This is an open-access article distributed under the terms of the Creative Commons Attribution License (CC BY). The use, distribution or reproduction in other forums is permitted, provided the original author(s) and the copyright owner(s) are credited and that the original publication in this journal is cited, in accordance with accepted academic practice. No use, distribution or reproduction is permitted which does not comply with these terms. 